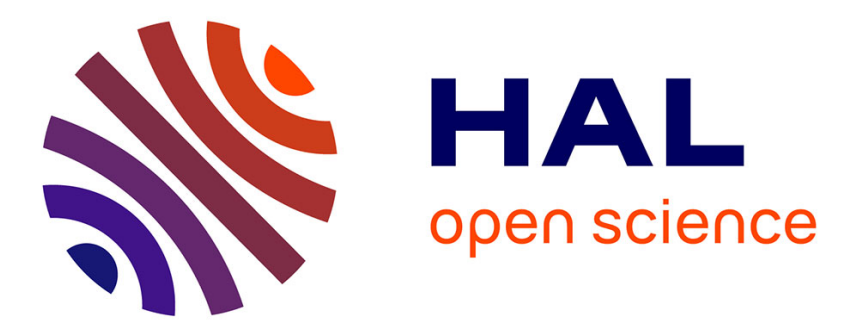

\title{
Tracking the volatile and magmatic history of Vesta from chromium stable isotope variations in eucrite and diogenite meteorites
}

Ke Zhu, Paolo Sossi, Julien Siebert, Frédéric Moynier

\section{- To cite this version:}

Ke Zhu, Paolo Sossi, Julien Siebert, Frédéric Moynier. Tracking the volatile and magmatic history of Vesta from chromium stable isotope variations in eucrite and diogenite meteorites. Geochimica et Cosmochimica Acta, 2019, 266, pp.598-610. 10.1016/j.gca.2019.07.043 . insu-02556481

\author{
HAL Id: insu-02556481 \\ https://hal-insu.archives-ouvertes.fr/insu-02556481
}

Submitted on 21 Dec 2021

HAL is a multi-disciplinary open access archive for the deposit and dissemination of scientific research documents, whether they are published or not. The documents may come from teaching and research institutions in France or abroad, or from public or private research centers.
L'archive ouverte pluridisciplinaire HAL, est destinée au dépôt et à la diffusion de documents scientifiques de niveau recherche, publiés ou non, émanant des établissements d'enseignement et de recherche français ou étrangers, des laboratoires publics ou privés.

\section{(ㄷ)(1) $\$$}

Distributed under a Creative Commons Attribution - NonCommerciall 4.0 International 
1 Tracking the volatile and magmatic history of Vesta from chromium stable isotope variations in eucrite and diogenite meteorites

$5 \quad{ }^{1}$ Institut de Physique du Globe de Paris, Université de Paris, CNRS, 1 rue Jussieu,

11 Key words: $\mathrm{Cr}$ isotopes, Vesta, chondrites, volatile elements, volatile history,

12 equilibrium fractionation, howardite-eucrite-diogenite, magma ocean 
Abstract

Although Solar System bodies exhibit large variations in their volatile element abundances, the mechanisms and conditions that lead to these variations remain ambiguous. The howardite-eucrite-diogenite (HED) meteorites that likely sample the asteroid 4 Vesta, provide evidence for extensive volatile depletion on their parent body. Isotopic variations in moderately volatile elements, such as $\mathrm{Zn}$, have been used to track the origin of such volatile loss. Although not nominally volatile, $\mathrm{Cr}$ is useful because it has several oxidized gas species that render it volatile under the oxidizing conditions that characterize planetary accretion. As such, volatile loss of $\mathrm{Cr}$ has the potential to produce an isotopically light evaporation residue under an equilibrium regime. This contrasts with other moderately volatile elements that show heavy isotope enrichments in the residue following both kinetic or equilibrium fractionation. Here, we report the Cr stable isotope composition of 11 eucrites and four diogenites. The eucrites possess systematically lighter $\mathrm{Cr}$ isotope compositions than diogenites, which is onset by the accumulation of isotopically heavy $\mathrm{Cr}^{3+}$-rich orthopyroxene and spinel in diogenites during their magmatic evolution. We estimate for the primary eucrite melt with $\mathrm{Mg \#} \approx$ 50, a $\delta^{53} \mathrm{Cr}\left({ }^{53} \mathrm{Cr} /{ }^{52} \mathrm{Cr}\right.$ deviation relative to NIST SRM 979 in per mile) of $-0.22 \pm 0.03 \%$ o (2SD), lighter than any chondritic meteorite group by $\sim 0.1 \%$. This deficit may result from either partial melting with residual $\mathrm{Cr}^{3+}$-bearing phases (e.g. chromite) that retain heavy isotopes, or from vapor loss that occurred at equilibrium with a magma ocean on Vesta. Isotopic fractionation during partial melting would necessitate implausibly high Cr contents in the Vestan mantle, and oxygen fugacities high enough to stabilize 
chromite in the mantle source. Isotopic fractionation during evaporation would require an oxidized vapor and a reduced residue, as predicted by thermodynamic constraints on the composition of the vapor phase above a silicate magma ocean. Therefore, this $\mathrm{Cr}$ isotopic deficit between Vesta and chondrites may be caused by $\mathrm{Cr}$ loss at relatively high oxygen fugacity in a gas phase at equilibrium with the liquid from which it evolved. Temperatures of volatile loss are estimated to be lower than $2300 \mathrm{~K}$, consistent with loss from a large-scale magma ocean model for formation of Vesta, which may be a common evolutionary stage in accreting planetesimals.

\section{Introduction}

Differentiated planetary bodies are characterized by a widespread depletion in their moderately volatile element abundances (e.g. O'Neill and Palme, 2008). The mechanisms and timing of this moderately volatile element depletion observed in the silicate fraction of differentiated bodies is still debated (e.g. O'Neill and Palme 2008; Hans et al., 2013; Day and Moynier, 2014; Siebert et al., 2018; Sossi and Fegley 2018)

Recent measurements of the stable isotope compositions of moderately volatile elements (such as $\mathrm{Zn}, \mathrm{Cl}, \mathrm{Ga}, \mathrm{K}, \mathrm{Rb}$ ) in planetary materials have provided new insights into the origin, and conditions of the volatile depletion in Solar System materials (Sharp et al., 2010; Paniello et al., 2012a; Kato et al., 2015; Wang and Jacobsen, 2016; Kato and Moynier, 2017; Pringle and Moynier, 2017; Boyce et al. 2018). These studies have found that, in general, moderately volatile elements were enriched in their heavier isotopes in volatile depleted bodies such as 4 Vesta (e.g. Paniello et al., 2012b; Pringle 
and Moynier, 2017; Sarafian et al., 2017; Tian et al., 2018) relative to their putative chondritic building-blocks. These results point toward evaporation during planetary processes such as impacts (e.g. Paniello et al., 2012a; Wang and Jacobsen, 2016), degassing during eruption (Sharp et al., 2010) or crystallization of a magma ocean (e.g. Day and Moynier, 2014; Boyce et al., 2015; Kato et al., 2015; Kato and Moynier, 2017) that are absent during chondrite formation.

Based on spectroscopic data, the howardite-eucrite-diogenite (HED) clan of meteorites are interpreted as samples of the crust of 4 Vesta, the second largest asteroid in the asteroid belt (McCord et al., 1970; Binzel and Xu, 1993; Beck et al. 2011; Russell et al., 2012). Eucrites are broadly basaltic rocks predominantly composed of pigeonite and plagioclase, derived from Vesta's crust, whereas diogenites are mostly orthopyroxenites, with some olivine-rich variants, and are conventionally viewed as cumulate igneous rocks formed in a magma ocean or during intrusive magmatism on Vesta; howardites are impact-brecciated mixtures of both (Mittlefehldt, 2015).

volatile elements as illustrated by $\mathrm{K} / \mathrm{U}$ and $\mathrm{Rb} / \mathrm{Sr}$ ratios $\sim 10$ times, and $\sim 100$ times lower than in CI chondrites, respectively (Day and Moynier, 2014; Mittlefehldt, 2014). There is limited data available on the stable isotope composition of moderately volatile elements in HEDs, e.g. Zn, Rb, Cl and Li (Magna et al., 2014; Paniello et al., 2012b; Pringle and Moynier, 2017; Sarafian et al., 2017). Zinc and Rb with 50\%-nebular condensation temperatures $\left(\mathrm{T}_{\mathrm{c}}\right)$ of $726 \mathrm{~K}$ and $800 \mathrm{~K}$, respectively (Lodders 2003) are 
enriched in the heavier isotopes in HED meteorites compared to chondrites (Paniello et al., 2012b; Pringle and Moynier, 2017). Chlorine $\left(\mathrm{T}_{\mathrm{c}}=948 \mathrm{~K}\right.$, Lodders 2003) isotope ratios correlate with major- (e. g. $\mathrm{Mg}$ and $\mathrm{Cr}$ ) and trace-element $(\mathrm{K}, \mathrm{Sc}$ and $\mathrm{Br}$ ) content, which suggests mineral (e. g. olivines and spinel) crystallization and volatile loss (e. g. $\mathrm{K}$ and $\mathrm{Br}$ ) during a magma ocean stage (Sarafian et al., 2017). All of the three isotope systems above point toward volatile depletion due to evaporation from 4 Vesta (Paniello et al., 2012b; Pringle and Moynier, 2017; Sarafian et al., 2017). On the other hand, Li with a $T_{c}$ of $1142 \mathrm{~K}$, is isotopically similar to chondrites (Magna et al., 2014). The absence of $\mathrm{Li}$ isotopic fractionation and limited $\mathrm{Li}$ loss would suggest that the temperature under which this occurred was relatively low (Magna et al., 2014). Based on Rb-Sr isotope dating, Hans et al. (2013) suggested that volatile loss occurred under solar nebula conditions, while others have argued for post-nebular loss under more oxidizing conditions (O'Neill and Palme, 2008; Moynier et al., 2012). Since both Zn and $\mathrm{Rb}$ have more reduced species $\left(\mathrm{Zn}^{0}\right.$ and $\left.\mathrm{Rb}^{0}\right)$ in the vapor compared to silicate melts $\left(\mathrm{Zn}^{2+}\right.$ and $\left.\mathrm{Rb}^{+}\right)$(Lamoreaux and Hildenbrand, 1984; Lamoreaux et al., 1987; Sossi et al. 2019), both equilibrium and kinetic evaporation would enrich these elements in the heavier isotopes in the condensed phase(s), because the vapor (compared to residue) and reduced species (compared to oxidized species) are both enriched in the lighter isotope. It is therefore not presently possible to discern between these two kinds of isotopic fractionation processes based on these isotopic systems. As recently applied by Sossi et al. (2018), Cr isotopes can be used to give insights into the mechanism of volatile depletion. Under oxidizing conditions $\left(f \mathrm{O}_{2}>\mathrm{IW}+1\right)$, relevant to planetary 

differentiation, as evidenced by experimental studies (Bonnand et al., 2016b) and the

evaporation (Visscher and Fegley, 2013), Cr may be present in the gas as oxide species $\mathrm{CrO}(\mathrm{g}), \mathrm{CrO}_{2}(\mathrm{~g})$ and $\mathrm{CrO}_{3}(\mathrm{~g})(\mathrm{Chase}, 1998)$ and equilibrium isotopic fractionation (Young et al., 2019) could cause enrichment of the lighter isotopes in the condensed phases, in which $\mathrm{Cr}$ is either di- or trivalent, relative to the vapor. This contrasts with its speciation under nebular conditions, in which $\mathrm{Cr}$ may be present as $\mathrm{Cr}^{2+}$ or $\mathrm{Cr}$ metal in the condensed phase and $\mathrm{Cr}^{0}$ in the gas. Sossi et al. (2018) have shown that the Moon is enriched in the lighter isotopes of Cr compared to Earth's mantle, its likely precursor, a feature ascribed to volatile loss under relatively oxidizing conditions, which cause $\mathrm{Cr}$ to be present as $\mathrm{CrO}_{2}$ in the vapor phase but predominantly as $\mathrm{Cr}^{2+}$ in the melt. Because this signature could only have resulted from equilibrium between liquid and gas, they were able to calculate that evaporation must have occurred at temperatures between 1600 and $1800 \mathrm{~K}$, implying that loss took place following cooling and accretion of the Moon. This contrasts with models that argue for volatile loss contemporaneous with a very hot (>4000 K) giant impact (Nakajima and Stevenson, 2014). Moreover, relative to other moderately volatile elements such as $\mathrm{Zn}$ or $\mathrm{K}$ (whose abundances in lunar basalts are $\sim 50(\mathrm{~K})$ to $\sim 300(\mathrm{Zn})$ times lower than those in chondrites; Paniello et al., 2012; Day and Moynier, 2014), the i) higher concentration of $\mathrm{Cr}$ (Wänke and Dreibus, 1980) and ii) its lower volatility (Sossi et al., 2018) facilitate precise isotopic analysis and make $\mathrm{Cr}$ less susceptible to overprinting by possible late accretion on Vesta. 
130 is not appreciably siderophile (e.g., Rammensee et al. 1983) except under very high

131 temperatures and/or reducing conditions (Wade and Wood, 2001; Mann et al. 2009;

132 Siebert et al. 2013). Therefore, isotopic variations in Cr likely reflect other processes,

133 such as magmatic differentiation and/or volatile depletion instead of core formation.

134 Studying the $\mathrm{Cr}$ isotopic composition of HED meteorites may be used to evaluate the 135 redox conditions during volatile loss of the HEDs and to estimate whether the 136 volatilization occurred during equilibrium or kinetic conditions, thereby potentially 137 constraining the temperature of evaporation. While there are no systematic studies of

138 the $\mathrm{Cr}$ isotope composition of eucrites and diogenites, the scarce data suggest a hint of 139 a light isotope enrichment in eucrites compared to diogenites and chondrites (Qin et al., 140 2015; Bonnand et al., 2016b). Here, we report high-precision Cr isotope compositions 141 of 11 eucrites and four diogenites analyzed via double-spike technique by Multi142 Collector Inductively-Coupled Plasma Mass Spectrometer (MC-ICP-MS) to better 143 quantify the magmatic and evaporation/condensation process that occurred during 144 Vesta's formation and constrain its physicochemical conditions.

\section{Samples and analytical methods}

\subsection{Samples}

Eleven eucrites and four diogenites were studied. The eucrites comprise

148 Pasamonte, Camel Donga, Stannern, Bouvante, Jonzac, Juvinas, EET 87548, Moore

149 County, Pomozdino, Serra de Magé and EET 87542, and the diogenites include EET 
151 group and Stannern trend (including Stannern, Pomozdino and Bouvante), have been

152 studied. The Stannern trend eucrites (on basis of their $\mathrm{Mg \#} \mathrm{(molar} \mathrm{Mg} /(\mathrm{Mg}+\mathrm{Fe})$ ) $\mathrm{Ti}$ and

153 incompatible trace element abundances) may be contaminated by Vestan crustal

154 materials (Barrat et al., 2007). Pasamonte was recognized as an anomalous eucrite

155 based on a different $\mathrm{O}$ isotopic composition compared to most HEDs (Greenwood et

156 al., 2009), suggesting that it may not have originated from Vesta or that Vesta is

157 isotopically heterogeneous. Most of the eucrites selected are monomict breccias, and

158 the sample descriptions are summarized in Table 1. Full replicates, including

159 dissolution, spike addition, and chemical purification of Pasamonte, Juvinas and Jonzac

160 were performed in order to test the overall reproducibility of the method. The $\mathrm{Cr}$

161 isotopic composition of three terrestrial geological reference materials, BHVO-2 and

162 DTS-1 and PCC-1 were analyzed to quantify the accuracy of the method.

\section{$163 \quad 2.2$ Methods}

164 All sample processing was performed in the clean laboratory at the Institut de

165 Physical du Globe de Paris (IPGP) following the method described in Sossi et al.,

166 (2018). Ten to $20 \mathrm{mg}$ of each meteorite sample were weighed from original powder of

$167 \sim$ g to ensure homogeneity. All eucrites were firstly dissolved in a mixture of HF and

$168 \mathrm{HNO}_{3}(2: 1)$ on a hot plate $\left(130{ }^{\circ} \mathrm{C}\right)$ for two days. Subsequently, the samples were

169 dissolved in aqua regia (concentrated $\mathrm{HCl}$ and $\mathrm{HNO}_{3}$ mixture in 3:1 ratio) to ensure

170 complete digestion. The four diogenites were dissolved by the concentrated mixed acid 
171 (HCl: $\left.\mathrm{HF}: \mathrm{HNO}_{3}=5: 3: 2\right)$ in Parr Bombs under pressurized steel jackets for four days

172 at $180{ }^{\circ} \mathrm{C}$, and no visible residues were observed. Then, the adequate amount of ${ }^{50} \mathrm{Cr}$ -

$173{ }^{54} \mathrm{Cr}$ double spike (28\% of the $\mathrm{Cr}$ content endemic to the sample) was added and the

174 solution and refluxed in closed PFA beakers at $120^{\circ} \mathrm{C}$ overnight. Half of the digested

175 samples were chemically purified for $\mathrm{Cr}$ via a two-step cation exchange

176 chromatography adapted from Trinquier et al. (2008), as routinely undertaken at IPGP

177 (Mougel et al., 2017; Mougel et al., 2018). This method has a total procedural yield of

$17860 \sim 90 \%$ and blank of $\sim 5 \mathrm{ng}$ of Cr. Compared to the total $10-60 \mu \mathrm{g}$ of $\mathrm{Cr}$, the blank is

179 negligible. The final $\mathrm{Cr}$ cut was evaporated in concentrated $\mathrm{HNO}_{3}$ drops three to five

180 times to convert the $\mathrm{HCl}$ medium to $\mathrm{HNO}_{3}$, and to remove leftover organics (i.e. resin),

181 and then diluted to a concentration of $1 \mathrm{ppm} \mathrm{Cr}$, in $2 \%(0.317 \mathrm{M}) \mathrm{HNO}_{3}$ for isotope 182 analysis.

183 The Cr stable isotope compositions of these purified samples were measured on a

184 Thermo Scientific Neptune Plus MC-ICP-MS housed at the IPGP, the details are 185 described in Sossi et al. (2018). The isotopic ratio for samples is compared to NIST 186 SRM 979 and reported in delta notation:

$$
\delta^{53} \operatorname{Cr}(\%)=\left(\frac{\left({ }^{53} C r /{ }^{52} C r\right)_{\text {sample }}}{\left({ }^{53} C r /{ }^{52} C r\right)_{\text {NIST SRM } 979}}-1\right) \times 1000
$$

188 The $\mathrm{Cr}$ isotopic composition of a secondary standard, NIST SRM 3112a, was also 189 measured in each analytical session to monitor the instrumental mass fractionation and 190 the precision of the data. The Cr isotopic composition of every sample was measured 
191

192

193

194

twice. Therefore, the Cr isotopic composition of samples for which 2 separate chemical purification procedures were performed (Stannern, Pasamonte, Juvinas and Jonzac) were analyzed four times (in figures, two replicate data for the four samples were combined as one). The uncertainties quoted for individual samples are 2SD of single sample measurements (100 cycles for two times) or 2SD reproducibility of several NIST SRM 979 measurements in the same analytical session $(0.04 \%$ ), or that of NIST SRM 3112a (0.04\%o), whichever is largest.

Since, when normalized to the ${ }^{50} \mathrm{Cr} /{ }^{52} \mathrm{Cr}$ ratio, $\mathrm{Cr}$ shows non-mass dependent isotopic effects on both the ${ }^{53} \mathrm{Cr} /{ }^{52} \mathrm{Cr}$ (due to the decay of ${ }^{53} \mathrm{Mn}$ ) and on ${ }^{54} \mathrm{Cr} /{ }^{52} \mathrm{Cr}$ (nucleosynthetic anomalies) ratios in HEDs (Trinquier et al., 2007), a correction must be applied in order to properly perform the double spike reduction. Most samples analyzed here had been previously studied for their ${ }^{53} \mathrm{Cr}$ and ${ }^{54} \mathrm{Cr}$ anomalies. For the samples (Camel Donga, EET 87548, Moore County, Pomozdino, Serra de Magé, EET 87542 and EET 79002), which have no available data, we have used the average of the ${ }^{54} \mathrm{Cr}$ anomalies which have been shown to be homogeneous between all HED analyzed, with an average value for $\varepsilon^{54} \mathrm{Cr}$ of -0.74 . Since ${ }^{53} \mathrm{Cr}$ is produced by the radioactive decay of ${ }^{53} \mathrm{Mn}$ (e.g. Zhu et al., 2019a; Zhu et al., 2019b), one single value cannot be applied and for the samples for which the ${ }^{53} \mathrm{Cr}$ anomalies were not available and the ${ }^{53} \mathrm{Cr}$ anomalies were estimated based on their ${ }^{55} \mathrm{Mn} /{ }^{52} \mathrm{Cr}$ ratio and from the slope of the ${ }^{53} \mathrm{Mn}$ ${ }^{53} \mathrm{Cr}$ isochron (Trinquier et al., 2008). 
212 (Scott et al., 2009; Sanborn and Yin, 2014). Sanborn and Yin (2014) reported $\varepsilon^{54} \mathrm{Cr}=-$

$2130.33 \pm 0.08$, while Trinquier et al. (2007) reported $-0.71 \pm 0.08$ on a different sample

214 section. However, it should be noted that whichever $\varepsilon^{54} \mathrm{Cr}$ values applied in the double

215 spike reduction only changes the calculated $\delta^{53} \mathrm{Cr}$ by 0.02 , which is smaller than the 2162 2SD error for NIST SRM 979. Furthermore, if the variation for $\varepsilon^{53} \mathrm{Cr}$ or $\varepsilon^{54} \mathrm{Cr}$ reaches

$2171 \varepsilon$ (the variation for $\varepsilon^{53} \mathrm{Cr}$ and $\varepsilon^{54} \mathrm{Cr}$ in HEDs is always less than $0.6 \varepsilon$ (Sanborn and Yin, 218 2014; Trinquier et al., 2007; 2008) and were not corrected, the final corrected $\delta^{53} \mathrm{Cr}$ 219 would only shift by $0.008 \%$ due to $\varepsilon^{53} \mathrm{Cr}$ and $0.038 \%$ due to $\varepsilon^{54} \mathrm{Cr}$ which would fall 220 within the analytical uncertainty $\left(0.04 \%\right.$ ). For consistency, we use only the $\varepsilon^{54} \mathrm{Cr}$ data 221 from Trinquier et al. (2007) for the samples for which $\varepsilon^{54} \mathrm{Cr}$ is unknown.

\section{Results}

The $\delta^{53} \mathrm{Cr}$ values, $\mathrm{Cr}$ contents and $\mathrm{Mg \#}$ of 11 eucrites (including seven non-

224 cumulate eucrites, three cumulate eucrites and one polymict eucrite) and five diogenites

225 (including one datum, from Bonnand et al. (2016b)) are reported in the Table 1. The $226 \delta^{53} \mathrm{Cr}$ for eucrite samples ranges from -0.13 to $-0.25 \%$, with an average value of -0.20 $227 \pm 0.08 \%$ (2SD, $\mathrm{n}=11)$, twice as large as the analytical uncertainty. Compared to 228 cumulate eucrites, the non-cumulate eucrites are characterized by lower $\mathrm{Cr}$ content, 229 lower $\mathrm{Mg \#}$ and lower $\delta^{53} \mathrm{Cr}$ than the diogenites. The five diogenite samples display 230 heavier $\delta^{53} \mathrm{Cr}$, with the LAP 03569 sample having the heaviest $\delta^{53} \mathrm{Cr}$ values of $-0.07 \pm$ $2310.04 \%$. There is no systematic difference in the $\mathrm{Cr}$ isotope composition between the 232 main group and Stannern trend eucrites when comparing the five monomict eucrites: 
233 Juvinas, Jonzac, Camel Donga, Stannern and Bouvante. Replicate analyses of the $\delta^{53} \mathrm{Cr}$

234 of Pasamonte, Juvinas, Jonzac and Stannern agree within error (see table 1). The $\delta^{53} \mathrm{Cr}$

235 of the USGS standards, BHVO-2, PCC-1 and DTS-1, are consistent with previously

236 reported values (Schoenberg et al., 2016; Sossi et al., 2018; Chen et al., 2019). When

$237 \delta^{53} \mathrm{Cr}$ values are reported as a function of $\mathrm{Cr}$ concentration (and $\mathrm{Mg} \#$ ), diogenites and 238 eucrites are clustered, with eucrites isotopically light and low in $\mathrm{Cr}(1750 \sim 5673 \mathrm{ppm})$

239 compared to the isotopically heavier and Cr-richer diogenites (4404 $6780 \mathrm{ppm})$

240 (Figure 1a). The Mg\# of the HED meteorites analyzed are also grouped into a high $241(\mathrm{Mg} \# \approx 75$, diogenites $)$ and a low $(\mathrm{Mg} \# \approx 40$, basaltic eucrites $)$ populations, with some 242 cumulate and magnesian eucrites spanning the gap between them (Figure 1b).

\section{4. Discussion}

\section{$244 \quad 4.1$ Heavy Cr isotope enrichment in diogenites}

Eucrites and diogenites are samples from the silicate fraction of Vesta (Keil, 2002;

246 Mittlefehldt, 2015). The isotopically heavier diogenites have higher $\mathrm{Cr}$ contents and

$247 \mathrm{Mg \#}$ relative to eucrites. This suggests that magmatic differentiation could have led to

248 the Cr isotopic difference between the two meteorite groups. Small variations on the 249 order of $0.1 \sim 0.2 \%$ are also found in lunar mare basalts and $\mathrm{Mg}$ suite cumulates 250 (Bonnand et al., 2016a; Sossi et al., 2018). Fractionation is generally more limited in

251 Earth's mantle $(-0.11 \pm 0.06 \%$; Schoenberg et al., 2008; Sossi et al., 2018), except 252 during metasomatic processes (Xia et al., 2017; Shen et al., 2018). Therefore, utilizing 253 the eucrites and diogenites to reconstruct the Cr isotopic composition of Vesta requires 
assessment of any isotopic fractionation that may have occurred during processes such as partial melting and fractional crystallization.

Partial melting on Earth involves isotopic exchange between both $\mathrm{Cr}^{2+}-$ and $\mathrm{Cr}^{3+}-$ bearing phases. In typical mantle peridotites that have equilibrated near the FayaliteMagnetite-Quartz (FMQ) buffer, the majority of $\mathrm{Cr}$ is present in its trivalent form in spinel and clinopyroxene ( $\mathrm{Li}$ et al., 1995). At the same $\mathrm{fO}_{2}$, basaltic melts have a greater proportion of $\mathrm{Cr}^{2+}$, about $\mathrm{Cr}^{2+} / \sum \mathrm{Cr}=0.3$ at $1400^{\circ} \mathrm{C}$ (Berry et al., 2006). The difference in $\mathrm{Cr}$ redox states $\left(\mathrm{Cr}^{2+}\right.$ and $\left.\mathrm{Cr}^{3+}\right)$ between residual mantle and melt thereby provides a mechanism for inducing $\mathrm{Cr}$ isotope fractionation (the heavier $\mathrm{Cr}^{3+}$ is highly compatible in some refractory minerals; e.g. chromite), in which the residue becomes isotopically heavier and the complementary liquids are relatively lighter. Shen et al. (2018) calculated the magnitude of this effect, and found a $\Delta^{53} \mathrm{Cr}_{\text {Mantle-Melt }}=+0.05 \%$ for degrees of melting around $15 \%$ (i.e., melts should be isotopically lighter than their sources). Nevertheless, observational evidence points to limited $\mathrm{Cr}$ isotope fractionation during partial melting near the FMQ buffer (Schoenberg et al., 2008) on the basis that both terrestrial basaltic rocks and peridotites have similar compositions.

On Vesta, basaltic eucrites have assemblages that reflect equilibration at lower $\mathrm{fO}_{2}$ relative to terrestrial magmas, $\approx 1 \log$ unit below the Iron-Wüstite buffer (e.g. Righter et al., 2016) yielding $\mathrm{Cr}^{2+} / \sum \mathrm{Cr} \approx 0.9$ in the melt using the calibration of Berry et al. (2006). Mineral phases in equilibrium with eucritic liquids (pyroxene-plagioclase \pm spinel \pm metal; Bartels and Grove, 1991; Stolper, 1977) have the majority of their $\mathrm{Cr}$ 
275 hosted in pyroxene and spinel. Even at IW-1, these phases will contain predominantly

$276 \mathrm{Cr}^{3+}$ (Karner et al., 2007). Should these minerals be present as residual phases during

277 partial melting to produce eucrites, then the large $\mathrm{Cr}^{2+} / \sum \mathrm{Cr}_{\text {melt }}>\mathrm{Cr}^{2+} / \sum \mathrm{Cr}_{\text {source }}$ should

278 enhance fractionation relative to terrestrial environments. The $\mathrm{Cr}^{2+} / \sum \mathrm{Cr}_{\text {source }}$ of the

279 Vestan mantle source will depend on the phase assemblage. A peridotitic source at IW-

2801 and $1400{ }^{\circ} \mathrm{C}$, would contain olivine with $\mathrm{Cr}^{2+} / \sum \mathrm{Cr} \approx 0.8$ to 0.9 (Bell et al. 2014), low-

281 Ca clinopyroxene with exclusively $\mathrm{Cr}^{3+}$ (Karner et al. 2007), with orthopyroxene

282 between these two extremes, conferring a weighted average $\approx 0.5$. The net effect is to

283 produce isotopically light partial melts, unless i) spinel is not stable at partial melting

284 temperatures ( $\mathrm{Li}$ et al., 1995) or ii) spinel and much of the pyroxene is completely

285 dissolved from eucrite parent magma source regions. If the $\mathrm{Cr}$ content of the Vestan

286 mantle is $\approx 2300 \mathrm{ppm}$ (see Jones (1984) and discussion below) and given that $\mathrm{D}_{\mathrm{Cr}}$

287 between mantle and melt is approximately unity (Hanson and Jones, 1984; Mallmann

288 and O'Neill, 2009), then the relatively high $\mathrm{Cr}$ content of main group eucrites $(\approx 2000$

289 ppm which mainly resides in spinel and pyroxene; Barrat et al., 2000) compared to

290 terrestrial basalts $(\approx 300 \mathrm{ppm})$ suggests it behaved as a moderately incompatible

291 element during partial melting on Vesta, implying spinel was not an important residual

292 phase. This is also borne out in the increasing $\mathrm{Cr}$ contents with progressive fractional

293 crystallization among main group eucrites (see Barrat et al., 2000). Importantly, the

294 melt phase thus leverages the Cr isotope composition of the system for eucrites, whereas

295 the majority of the Cr remains in the mantle during partial melting on Earth. However,

296 the effect of partial melting cannot be excluded, and would produce partial melts with 

307 be understood. lighter $\mathrm{Cr}$ isotope compositions than their sources (Figure 2).

To interpret the causes of $\mathrm{Cr}$ isotope variations in eucrites and diogenites requires understanding of their petrogenesis. One prevailing hypothesis states that diogenites and eucrites originated from an early Vestan magma ocean, and melts parental to eucrites were formed followed by crystallization of cumulate pyroxenes, which would imply that diogenites and eucrites were cogenetic (Mason, 1967; Righter and Drake, 1997; Mandler and Elkins-Tanton, 2013). However, the diversity in diogenite compositions have been used as evidence to preclude a direct link to eucrites (Stolper, 1977; Barrat et al. 2008). Therefore, in order to determine the $\mathrm{Cr}$ isotope composition of Vesta, the effects of fractional crystallization in fractionating $\mathrm{Cr}$ isotopes must first

The majority of diogenites are coarse-grained ultramafic rocks dominated by magnesian orthopyroxenes and minor olivine, silica and spinel (Bowman et al., 1997; Beck and Mcsween, 2010), while eucrites are mainly comprised of orthopyroxene, pigeonite, low-Ca pyroxenes, plagioclases and minor silica, ilmenite and spinel (Delaney et al., 1984; Mittlefehldt, 2015). Among these minerals, pyroxene (both orthopyroxenes and clinopyroxenes) and chromite are the main carrier phases for $\mathrm{Cr}$, and together account for more than $98 \%$ of the Cr budget in eucrites and diogenites, as will be discussed below. In detail, the pyroxenes, which account for $40 \sim 60 \%$ in mass of eucrites (including orthopyroxene, pigeonite and high-Ca pyroxene), contain an average of $0.32 \mathrm{wt} \% \mathrm{Cr}_{2} \mathrm{O}_{3}$, while plagioclase ( $40 \%$ of eucrites) are mostly $\mathrm{Cr}$-free 
318 (Mayne et al., 2009). Despite spinel being a minor mineral in eucrites (0.3\% in mode),

319 it can contain $\sim 45 \mathrm{wt} \%$ of $\mathrm{Cr}_{2} \mathrm{O}_{3}$, and is therefore an important $\mathrm{Cr}$ contributor to bulk

320 eucrites. Ilmenite is another Cr-bearing mineral ( $\sim .4 \mathrm{wt} \%$ of $\mathrm{Cr})$, but its proportion in

321 eucrites is only $\sim 0.7 \%$ (Mittlefehldt, 2015), of which $\mathrm{Cr}$ contribution to bulk rock is

322 less than $1 \%$. Relative to eucrites, diogenites have different mineral modes and

323 compositions. Most diogenites comprise 85 99\% orthopyroxene, which have on

324 average $0.41 \mathrm{wt} \%$ of $\mathrm{Cr}_{2} \mathrm{O}_{3}$, and $0.7 \%$ spinels that can hold up to $55 \mathrm{wt} \%$ of $\mathrm{Cr}_{2} \mathrm{O}_{3}$ in

325 diogenites (Beck and McSween, 2010; Day et al., 2012). In both eucrites and diogenites,

326 the ratio, $[\mathrm{Cr}]_{\text {pyroxene: }}[\mathrm{Cr}]_{\text {spinel, }}$, is close to $1: 1$.

Chromite (Cr-spinel) hosts exclusively $\mathrm{Cr}^{3+}$ in octahedral coordination that confers

328 a normal site distribution on spinel. Its formation from the melt can be described

329 following Roeder and Reynolds (1991) as:

$$
\mathrm{MgO}(\mathrm{l})+2 \mathrm{CrO}_{1.5}(\mathrm{l})=\mathrm{MgCr}_{2} \mathrm{O}_{4}(\mathrm{~s}) \cdot(2)
$$

331 The activity of $\mathrm{CrO}_{1.5}$ in the melt is related to $f \mathrm{O}_{2}$ by homogeneous equilibrium with 332 CrO:

$$
\mathrm{CrO}(\mathrm{l})+1 / 4 \mathrm{O}_{2}=\mathrm{CrO}_{1.5}(1)
$$

As reaction (3) is associated with a strongly negative change in entropy, $\Delta \mathrm{S}^{\circ}{ }_{(3)}(\mathrm{Li}$

335 et al. 1995), the crystallization of Mg-rich, Cr-spinel is favoured at i) high $\mathrm{fO}_{2}$ and ii)

336 low temperatures. Trivalent $\mathrm{Cr}$ is also preferentially incorporated into pyroxene 337 (Mallmann and O'Neill, 2009), that is to say, $\mathrm{Cr}^{3+} / \mathrm{Cr}^{2+}{ }_{\mathrm{px}, \text { spinel }}>\mathrm{Cr}^{3+} / \mathrm{Cr}^{2+}$ melt. Chromium 
338 isotope fractionation occurs between the $\mathrm{Cr}^{2+}$ - and $\mathrm{Cr}^{3+}$-containing melt, and 339 predominantly $\mathrm{Cr}^{3+}$-bearing phases due to differences in bonding environment between 340 the two phases. Trivalent $\mathrm{Cr}$ has high octahedral site preference energy (OSPE) and 341 hence is found solely in VI-fold sites in both minerals and melt (e.g., Berry and O'Neill, 342 2004). The coordination chemistry of divalent Cr is dictated by its tendency for Jahn343 Teller distortions, therefore preferring irregular bonding environments (e.g. Burns, 344 1975). Indeed, $\mathrm{Cr}^{2+}$ is distributed subequally on the M1 and M2 sites of olivine, due to 345 its competing preferences for the larger M2 site and the more distorted M1 site (Li et 346 al., 1995). However, in pyroxenes, the M2 site is both larger and more distorted than 347 the M1, meaning $\mathrm{Cr}^{2+}$ is strongly partitioned onto the M2 site (Angel et al., 1989). Its 348 coordination in silicate melts is uncertain, though it may be coordinated by six oxygens 349 in a square planar arrangement (O'Neill and Berry, 2006). Since $\mathrm{Cr}^{3+}(r=0.615 \AA)$ 350 exists as 6-fold coordination in all minerals (olivine, pyroxene and spinel) and has 351 shorter M-O distances as compared to $\mathrm{Cr}^{2+}(r=0.80 \AA)$, which exists in larger, more 352 distorted geometries, the $\mathrm{Cr}^{3+}$ phases should be isotopically heavier. The preferential 353 incorporation of $\mathrm{Cr}^{3+}$ into orthopyroxene and $\mathrm{Cr}$-spinel relative to the melt leads to 354 isotope fractionation between them and provides a mechanism to explain the heavier 355 isotopic composition of diogenites compared to the eucrites. In terrestrial peridotites, 356 chromites (which host entirely $\mathrm{Cr}^{3+}$ ) are isotopically heavier compared to the bulk 357 (Farkaš et al., 2013; Schoenberg et al., 2008), which is further confirmed by the 358 following general $\delta^{53} \mathrm{Cr}$ order: chromite-free peridotites $(-0.21 \%$ $-0.11 \%$ o $<$ 359 chromite-bearing peridotite $(-0.07 \%$ ) $\leq$ chromite $(-0.06 \%$ ) (Shen et al., 2015) and by 
360 ab initio calculations (Moynier et al., 2011). If a primary melt from the Vestan mantle

361 formed at IW-1, it should only possess $\sim 10 \% \mathrm{Cr}^{3+}$ (Berry et al., 2006; Wadhwa, 2008).

362 Therefore, the isotopically heavy pyroxenes and spinels in diogenites rapidly uptake

363 most of the limited budget of $\mathrm{Cr}^{3+}$ compared to those in eucrites, producing isotopically

364 heavier diogenites.

365 4.2 The Cr isotopic composition of the bulk Vesta

366 HED meteorites are likely direct samples from Vesta (McCord et al., 1970; Binzel

367 and $\mathrm{Xu}, 1993$; Russell et al., 2012), but their chemical variation means that estimating

368 the isotopic composition of the Vestan mantle hinges upon identifying samples that have

369 undergone minimal isotopic fractionation relative to their mantle sources. Samples that

370 are most likely to fulfil these criteria are those that represent primary melts, i.e., those

371 in equilibrium with their mantle sources. Among eucrites, the cumulate varieties

372 (including EET 87548) with high Mg\#s (54), have accumulated $\mathrm{Cr}^{3+}$-bearing minerals

373 (chromite, pyroxene), that have resulted in an increase in $\mathrm{Cr}$ content relative to their

374 parent magma. Because this accumulation could cause $\mathrm{Cr}$ isotope fractionation ( $c f$. Fig.

3751 and section 4.1.), these samples are excluded from the determination of the Vestan

376 mantle composition.

377 In order to quantify the magnitude of this effect, the ab-initio calculations of

378 Moynier et al. (2011) are used to show that chromite should be isotopically heavier than

379 co-existing $\mathrm{Cr}^{2+}$-bearing silicates by about $0.15 \%$ at magmatic temperatures

380 (1200 1400 ${ }^{\circ} \mathrm{C}$; Moynier et al., 2011). The heaviest diogenites have $\delta^{53} \mathrm{Cr}$ of $-0.07 \%$ o 
381 (LAP 03569 and Johnstone), which are, at most, $0.15 \%$ o heavier relative to eucrites. If 382 one considers that a primary melt of the Vestan mantle contains $90 \% \mathrm{Cr}^{2+}$ (Berry et al. 383 2006), then the diogenites, as cumulates that contain only $\mathrm{Cr}^{3+}$, can represent no greater 384 than $10 \%$ by mass of the initial melt. If, in a closed system with a finite Cr budget, the 385 eucrites are complementary to diogenites (which appears not to be the case; Barrat et 386 al. 2008), then they would contain the other $90 \%$ of the $\mathrm{Cr}$ budget, and the $\mathrm{Cr}$ isotope 387 composition of the parental melt would be given by mass balance: $\delta^{53} \mathrm{Cr}_{\text {parental }}=$ $388 \delta^{53} \mathrm{Cr}_{\text {eucrite }} \times 0.9+\delta^{53} \mathrm{Cr}_{\text {diogenite }} \times 0.1$, which yields $-0.20 \%$, within statistical uncertainty 389 of the eucrite average $(-0.22 \pm 0.03 \%$ )

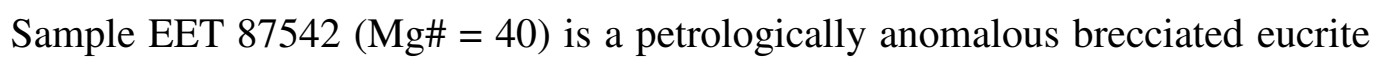

391 with low Fe/Mn-pyroxene, which underwent unusual subsolidus processing 392 (Mittlefehldt et al., 2015; 2016) that could have modified its Cr isotope composition. 393 Pasamonte has anomalous $\Delta^{17} \mathrm{O}$ and hence may not originate from Vesta (Scott et al., 394 2009), so it cannot be relied upon as a faithful probe of the composition of Vesta. Then, 395 it should be noted that Stannern and Bouvante belong to Stannern Trend, which, 396 although they may indeed be primary Vestan "mantle" melt products, have incorporated 397 crustal material (Barrat et al., 2007) that compromises the degree to which they 398 represent the Vestan mantle and are also excluded. Finally, this leaves three basaltic 399 Main trend basaltic eucrites (Juvinas, Jonzac and Camel Donga, Mg\# = 40-42). We 400 assess below whether these samples are representative of their sources.

401 On the basis that many of the main group eucrites' bulk compositions plot near the 
4021 atm peritectic, saturated in olivine-low Ca pyroxene-plagioclase-spinel-metal, Stolper 403 (1977) made a convincing case for the derivation of these magmas via partial melting 404 of the Vestan mantle. In this model, the most magnesian of these magmas, Sioux County 405 and Juvinas (and similar non-cumulate eucrites with $\mathrm{Mg \# s} \approx 42$ ), are produced by 15$40620 \%$ melting, whereas more evolved examples, such as Pasamonte and Nuevo Laredo 407 are liquid residues after moderate degrees $(<40 \%)$ of fractional crystallization. However, 408 later cosmochemical models postulate Mg\#s for the Vestan mantle between 75-80 409 (Dreibus and Wänke, 1980; Ruzicka et al., 1997). Whether these magmas are 410 representative of the mantle of Vesta can be assessed using $\mathrm{K}_{\mathrm{D}} \mathrm{Fe}-\mathrm{Mg}$ systematics 411 between mafic minerals and melt:

$$
K_{D, \text { Min-Melt }}^{F e-M g}=\frac{\left(\frac{F e}{M g}\right)_{M i n}}{\left(\frac{F e}{M g}\right)_{M e l t}}
$$
Experimental studies have shown that this value is close to 0.30 for olivine-melt 414 (Toplis, 2005), orthopyroxene-melt and clinopyroxene-melt (Bédard, 2007; Bédard, 415 2010). Application of equation (4) results in the expectation that primary melts of the 416 Vestan mantle should have Mg\#s between 45 and 55, that is, slightly higher than any of 417 the non-cumulate eucrites (36 42). This was pointed out by (Bartels and Grove, 1991), 418 who suggested that the non-cumulate eucrites may come from a more iron-rich region 419 of the Vestan mantle. Therefore, in lieu of non-cumulate samples that have Mg\#s 420 compatible with their direct derivation from mantle representative of bulk silicate Vesta, 421 we adopt the most magnesian eucrites analyzed, Juvinas, Jonzac and Camel Donga, as 422 most representative of Vesta, though the caveats mentioned above should be 
423

considered. From these lines of reasoning we consider bulk silicate Vesta to have $\delta^{53} \mathrm{Cr}$ $=-0.22 \pm 0.03 \%$.

\subsection{Difference in the Cr isotope compositions of Vesta and chondrites caused by} evaporation under oxidizing conditions.

Chondrites, commonly considered to be the building blocks of planetary bodies, have homogeneous $\delta^{53} \mathrm{Cr}$ within error, with values ranging from -0.05 to $-0.15 \%$ (Qin et al., 2015; Bonnand et al., 2016b; Schoenberg et al., 2016) and $\mathrm{Cr}$ contents varying from $2650 \mathrm{ppm}$ in CI chondrites to $\approx 3800 \mathrm{ppm}$ in ordinary chondrites (Wasson and Kallemeyn, 1988). Therefore, the choice of a specific chondrite group to represent the composition of Vesta is of secondary importance in discussing the Cr elemental and isotopic disparity between Vesta and its building blocks. However, since ordinary chondrites (OC) possess the closest non-mass dependent $\mathrm{Cr}$ and $\mathrm{Ti}$ isotopic compositions $\left(\varepsilon^{54} \mathrm{Cr}\right.$ and $\varepsilon^{50} \mathrm{Ti}$; Trinquier et al., 2007; 2009; Pedersen et al., 2019) to those of the HED meteorites, it is more logical to treat this group of chondrites as the building blocks of Vesta. Ordinary chondrites with $\delta^{53} \mathrm{Cr}=-0.12 \pm 0.03 \%$ ( $2 \mathrm{SD}, \mathrm{N}=6$; Bonnand et al., 2016b) are isotopically heavier than the estimate of the composition of the bulk silicate Vesta $(-0.22 \pm 0.03 \%$ o .

Ordinary chondrites have Cr contents of $\sim 3750$ ppm (Kallemeyn et al., 1989). The Cr content of Vesta's mantle is a matter of debate, with estimates of $\sim 2300 \mathrm{ppm}$ (Jones, 1984) to $\approx 7000 \mathrm{ppm}$ (see Mandler et al. (2013). As touched upon in section 4.1., the 
445 spinel exhaustion at- or near their liquidus temperatures and hence $\mathrm{D}_{\mathrm{Cr}} \approx 1$. The models

446 estimating higher Cr content in Dreibus and Wanke (1984); Ruzicka et al. (1997) and

447 Mandler et al. (2013) are predicated on determining the composition of Vesta from

448 binary mixtures of eucrites and diogenites and/or finding the point at which refractory

449 lithophile elements are present in chondritic proportions. This approach implicitly

450 neglects elemental fractionation during partial melting (eucrites) or mineral

451 accumulation (diogenites) and should be treated with caution, and only the model of

452 Jones (1984) considered the behaviour of $\mathrm{Cr}$ during partial melting. Additionally, $\mathrm{Cr}$

453 contents upwards of those of chondrites (> $4000 \mathrm{ppm}$ ) are difficult to justify given the

454 small size of the Vestan core (Russell et al. 2012). We therefore adopt the estimate of

455 Jones (1984), which is similar to $\mathrm{Cr}$ contents of the three representative eucrites

456 (Juvinas-2100 ppm, Jonzac-2501 ppm and Camel donga-2232 ppm). Normalized to Al

457 (a refractory element) and OCs, the fraction (f) of $\mathrm{Cr}$ in Vesta is $\sim 0.43$ (Al content for

458 Vesta's mantle and OCs are $16941 \mathrm{ppm}$ and $11900 \mathrm{ppm}$ respectively; $\mathrm{f}=\mathrm{Cr}_{\text {Vesta }} / \mathrm{Al}_{\text {Vesta }}$

$459 /\left(\mathrm{Cr}_{\text {Vesta }} / \mathrm{Al}_{\text {Vesta }}+\mathrm{Cr}_{\mathrm{OC}} / \mathrm{Al}_{\mathrm{OC}}\right)$. The origin of this deficit of $\mathrm{Cr}$ and the shift toward and

460 enrichment in the lighter $\mathrm{Cr}$ isotopes, with a $\Delta^{53} \mathrm{Cr}_{\text {Vesta-OC }}=-0.10 \pm 0.04 \%$, between

461 Vesta and OC is discussed below (Figure 3).

462 Chromium behaves as a slightly siderophile element under reduced conditions and 463 high temperatures (Wood et al., 2008). Vesta experienced core-mantle differentiation 464 (Russell et al., 2012), which had the potential to cause Cr isotope fractionation (Moynier 465 et al., 2011). Using the parameterization of Siebert et al. (2013), the metal-silicate 
466

partition coefficient (D) of $\mathrm{Cr}$ at conditions of core formation on asteroid 4-Vesta ( $2000 \mathrm{~K}$ and IW-1; pressure effect on Cr partitioning is negligible) is estimated to be $\mathrm{D}_{\mathrm{Cr}}=0.11 \pm 0.04$. Considering a core mass fraction of 0.18 for Vesta (Russell et al., 2012) and a bulk silicate Vesta Cr content of 2300 ppm (Jones, 1984), this partitioning value results in a Cr-poor Vestan core containing $262 \pm 80 \mathrm{ppm}$ of $\mathrm{Cr}$, which represents roughly 1 3\% of the Cr budget of Vesta. Accordingly, the formation of Vesta's core was likely ineffective in producing the $\mathrm{Cr}$ depletion or isotope fractionation relative to OCs, particularly when considering the small- to negligible $\mathrm{Cr}$ isotope fractionation between metal and silicate at $2000 \mathrm{~K}$ (Moynier et al., 2011; Bonnand et al., 2016b).

Thermodynamic modelling shows that high oxygen fugacity, near the FMQ buffer, should be a ubiquitous feature of any silicate melt-vapour disk at high temperatures (>1800 K) (Visscher and Fegley Jr, 2013). These higher oxygen fugacities relative to those of the solar nebular gas promote the evaporation of Cr (Sossi et al. 2019). At these conditions (near FMQ), $\mathrm{Cr}$ in the gas should mainly exist as $\mathrm{CrO}_{2}$ according to calculations made with thermodynamic data for homogeneous equilibria involving $\mathrm{Cr}$, $\mathrm{CrO}, \mathrm{CrO}_{2}$ and $\mathrm{CrO}_{3}$ gas species from the JANAF tables (Chase, 1998). If we consider that $90 \%$ of the $\mathrm{Cr}$ in the condensed phase is divalent, the appropriate evaporation equation is:
$\mathrm{CrO}(l)+1 / 2 \mathrm{O}_{2}=\mathrm{CrO}_{2}(g) .(5)$

85 Sossi et al. (2018) estimated the equilibrium fractionation factor of ${ }^{53} \mathrm{Cr} /{ }^{52} \mathrm{Cr}$ between $\mathrm{CrO}(\mathrm{l})$ and $\mathrm{CrO}_{2}(\mathrm{~g})$ using bond valence theory to be: 


$$
\Delta^{53} \operatorname{Cr}_{\operatorname{CrO}(l)-\operatorname{CrO}(g)}=(-0.31 \pm 0.16) \times \frac{10^{6}}{T^{2}} \quad(\% 0)
$$
The composition of the Vestan mantle in equilibrium with a $\mathrm{CrO}_{2}$-bearing gas phase can be calculated by mass balance in which: As explained above, $\delta^{53} \mathrm{Cr}_{\text {system }}$ is taken to be the average of ordinary chondrites $(-0.12 \pm 0.03 \% o), \delta^{53} C r_{\text {silicate Vesta }}$ is $-0.22 \pm 0.03 \%$, and $f_{\text {silicate Vesta }}^{C r}$ is $\sim 0.43$, 493 yielding $\delta^{53} C r_{\text {vapour }}=-0.04 \pm 0.03 \%$ and $\Delta^{53} \operatorname{Cr}_{\operatorname{CrO}(l)-\operatorname{CrO}(g)}=-0.18 \pm 0.04 \%$. 494 Solving Equation (6) for temperature and propagating uncertainties yields a 495 temperature of $1300 \pm 500 \mathrm{~K}$. A similar rationale can be applied using another type of 496 chondrite as representative of bulk Vesta. For example, the most extreme case, using CI 497 chondrites with $\mathrm{Cr}$ and $\mathrm{Al}$ content of $2630 \mathrm{ppm}$ and $8600 \mathrm{ppm}$ respectively (Wasson 498 and Kallemeyn, 1988) and $\delta^{53} \mathrm{Cr}$ value of $-0.15 \pm 0.01$ (Bonnand et al., 2016b) gives a 499 $f_{\text {silicate Vesta }}^{C r}=\sim 0.44, \delta^{53} \operatorname{Cr}_{\text {vapour }}=-0.09 \pm 0.03 \%$ and $\Delta^{53} \operatorname{Cr}_{\operatorname{CrO}(l)-\operatorname{CrO} 2(g)}=-$ $500 \quad 0.13 \pm 0.04 \%$. According to equation (6), the temperature range is $1550+750 /-600 \mathrm{~K}$ 501 (Figure 4). These two extreme models show that the volatile loss of Vesta occurred 502 under relatively cool conditions $(<2300 \mathrm{~K})$ and likely near the liquidus of basaltic 503 magma $(\approx 1500 \mathrm{~K})$. These relatively low temperatures for Vesta's volatile loss can be reconciled with 505 a degassing process during a magma ocean stage instead of a high-temperature giant 506 impact $(\approx 4000 \mathrm{~K}$; Nakajima and Stevenson, 2014). Volcanic eruptions and magmatic 
507 fire fountains may also contribute to volatile loss on a local scale (Day and Moynier, 508 2014). However, the three basaltic eucrites with homogeneous $\delta^{53} \mathrm{Cr}$ and distinct trace 509 element abundance (Barrat et al., 2000) and different cosmic ray exposure ages (9.5 Ma 510 for Juvinas, 31.4 Ma for Jonzac and 38.5 Ma for Camel Donga; Eugster and Michel, 511 1995) most probably come from different regions of Vesta, so localized degassing 512 processes are not consistent with the $\mathrm{Cr}$ isotopic data. Furthermore, considering that the 513 volatile degassing process must occur before Vestan crust formation, magmatic 514 degassing should predate the magmatic differentiation of the HEDs that lead to co515 variations between $\delta^{53} \mathrm{Cr}$ and $\mathrm{Mg} \#$ between eucrites and diogenites.

The homogeneous oxygen isotope compositions in HEDs suggests a widespread 517 magma ocean on Vesta (Greenwood et al., 2005; 2014), which is consistent with the $\mathrm{Cr}$ 518 isotopic evidence in this study. $\mathrm{Al}-\mathrm{Mg}$ and $\mathrm{Mn}-\mathrm{Cr}$ ages for bulk HED meteorites 519 indicate that Vesta differentiated very early, 1 3 Ma after CAIs (the first solids formed 520 in the Solar System), and these old Al-Mg and Mn-Cr ages should reflect the crust521 mantle differentiation after early magma ocean (Trinquier et al., 2008; Schiller et al., 522 2011; Day et al., 2012; Hublet et al., 2017; Schiller et al., 2017). An early-formed 523 carapace or shell formed via radiative cooling from the surface could effectively shut524 off evaporation, however, numerical calculations show that these skins are of the order 525 of a few centimeters thick and prone to foundering (Hin et al. 2017), and therefore do 526 not restrict outgassing from small rocky bodies. As such, the late formation of the 527 Vestan crust shows that the volatile depletion on Vesta must have occurred before the crystallization of the magma ocean, which is consistent with volatile loss ages, within 
$530 \mathrm{Mg}$ isotope enrichment observed (Hin et al., 2017; Dhaliwal et al., 2018). However, the

531 magma ocean model is challenged by considering the physical principles of planetary

532 accretion and geochemical and petrological evidence from meteorites (Lunning et al.,

533 2015; Wilson and Keli, 2017), which suggest that magma oceans are not ubiquitous

534 occurrence during planetary formation. If so, then the volatile depletion of Vesta may

535 have been imposed by accretion of material depleted in the solar nebula (Bloom et al.,

536 2018). However, the nebular gas is very reduced (with $\log f \mathrm{O}_{2}=-18.1$ at $1500 \mathrm{~K}$, or IW-

537 6.8; Grossman et al. 2008), and under such conditions, neither $\mathrm{Mn}$ nor $\mathrm{Cr}$ are

538 appreciably volatile. It would therefore be difficult to explain the super-chondritic

$539 \mathrm{Mn} / \mathrm{Na}$ of Vesta (O’Neill and Palme, 2008). Furthermore, $\mathrm{Cr}$ in condensed phases

540 would be expected to be, on average, more oxidized (a combination of $\mathrm{Cr}^{2+}$ and $\mathrm{Cr}$

541 metal) relative to the gas phase $\left(\mathrm{Cr}^{0}\right)$, such that equilibrium isotope fractionation would

542 result in heavy $\mathrm{Cr}$ in the solid residue. In this way, $\mathrm{Cr}$ in Vesta should be isotopically

543 heavier than chondrites, which is not consistent with the light $\mathrm{Cr}$ isotope compositions

544 in HEDs. As highlighted above, it cannot be excluded that the eucrites come from a

545 fractionated, Fe-rich part of the Vestan mantle, or that there is resolvable $\mathrm{Cr}$ isotope

546 fractionation during partial melting. Finally, the $\mathrm{Cr}$ isotopic study in eucrites and

547 diogenites supports the large-scale magma ocean caused the volatile depletion, and

548 magma oceans should play a critical role in determining the volatile element contents

549 of bodies formed in the early Solar System (Hin et al. 2017; Dhaliwal et al. 2018; Young 550 et al. 2019). 
This work reports high-precision $\mathrm{Cr}$ stable isotope compositions of bulk eucrites

553 and diogenites. It shows that eucrites are isotopically lighter than diogenites, and that

554 their $\mathrm{Cr}$ isotope compositions are correlated with the $\mathrm{Cr}$ content and $\mathrm{Mg \# \text {,which }}$ 555 suggests crystallization modified the $\mathrm{Cr}$ isotope composition of magmas on Vesta. This 556 systematics is reconciled with isotopically heavy $\mathrm{Cr}^{3+}$ entering orthopyroxene that 557 characterizes diogenites, whereas the eucrites represent both parental partial melts of 558 the Vestan mantle, and some later differentiates that contain predominantly $\mathrm{Cr}^{2+}$. eucrites likely provide the best indication as to the composition of the mantle of Vesta.

561 However, the Cr isotope composition deduced for Vesta based on these samples $(-0.22$ $562 \pm 0.03 \%$ o $)$ is lighter than that of its potential building blocks, ordinary chondrites $(-0.12$

$563 \pm 0.03 \%$ o). This deficit may arise due to $i$ ) partial melting in which residual $\mathrm{Cr}^{3+}$-bearing 564 phases in the Vestan mantle sequester the heavy isotopes or ii) vapor loss during 565 equilibrium with a magma ocean on Vesta. The former requires very high $\mathrm{Cr}$ contents 566 in the Vestan mantle, and that partial melting occurred at oxygen fugacities high enough 567 to stabilize chromite in the mantle source. By contrast, equilibrium fractionation of $\mathrm{Cr}$ 568 isotopes necessitates an oxidized vapor and reduced residue, consistent with 569 thermodynamic constraints of the composition of the vapor phase above a silicate 570 magma ocean. If correct, this model suggests a relatively low temperature for the 571 volatile degassing process $(<2300 \mathrm{~K})$ that lead to the impoverishment and light isotope 
572 composition of $\mathrm{Cr}$. This result argues that magma ocean degassing may be ubiquitous

573 during the accretionary stages of small telluric bodies.

574 
We thank the ERC under the European Community's H2020 framework

577 program/ERC grant agreement (no. 637503, Pristine) and the French National Research

578 Agency (ANR) for a Chaire d'Excellence Sorbonne Paris Cité (no. IDEX13C445) and

579 for the UnivEarthS Labex program (no. ANR-10-LABX-0023 and ANR-11-IDEX-

580 0005-02). Parts of this work were supported by IPGP multidisciplinary program PARI,

581 and by Region île-de-France SESAME Grant (no. 12015908). Julien Siebert

582 acknowledges funding from the ANR project VolTerre (no. ANR-14-CE33-0017-01).

583 Assistance on mass spectrometry from Pascale Louvat was also appreciated. We are 584 also grateful to insightful comments from Martin Schiller, James Day and another two 585 anonymous reviewers and editorial handling by Associate Editor James Day and Guest

586 Editor Mahesh Anand. Ke Zhu acknowledges a Ph.D. fellowship from China 587 Scholarship Council (no. 201706340161). 

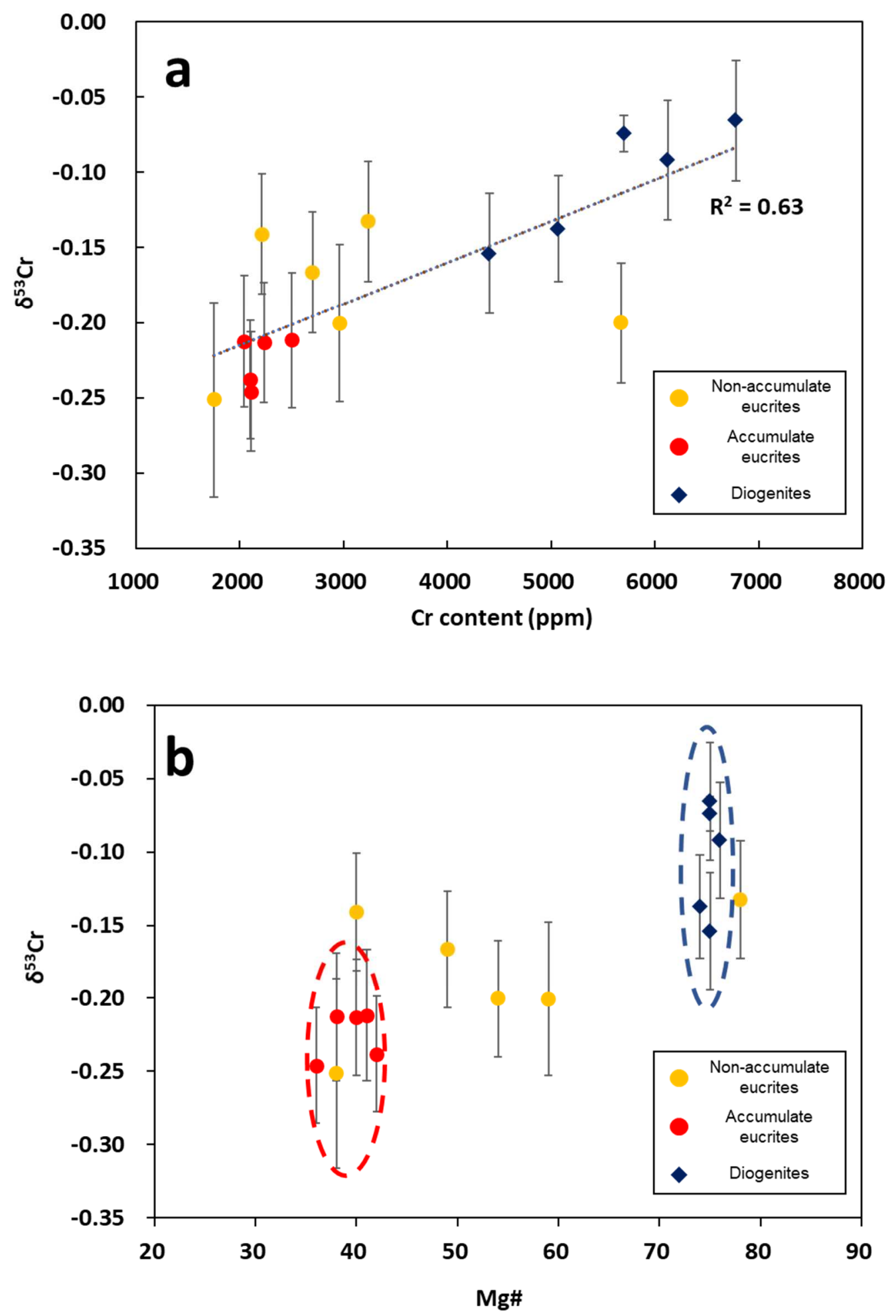

Figure 1 a. Chromium isotope composition vs. Cr content in HED samples. b. Cr 595 isotopes composition vs. Mg\# in HED samples. Red circles: non-accumulate eucrites, 596 yellow circles: cumulate eucrites and blue diamonds: diogenites. The red circle 597 indicates the reservoir for basaltic eucrites with low $\mathrm{Mg \#}$ and light $\mathrm{Cr}$, while the blue 598 circle is for the diogenites with high $\mathrm{Mg} \#$ and isotopically heavy $\mathrm{Cr}$. 

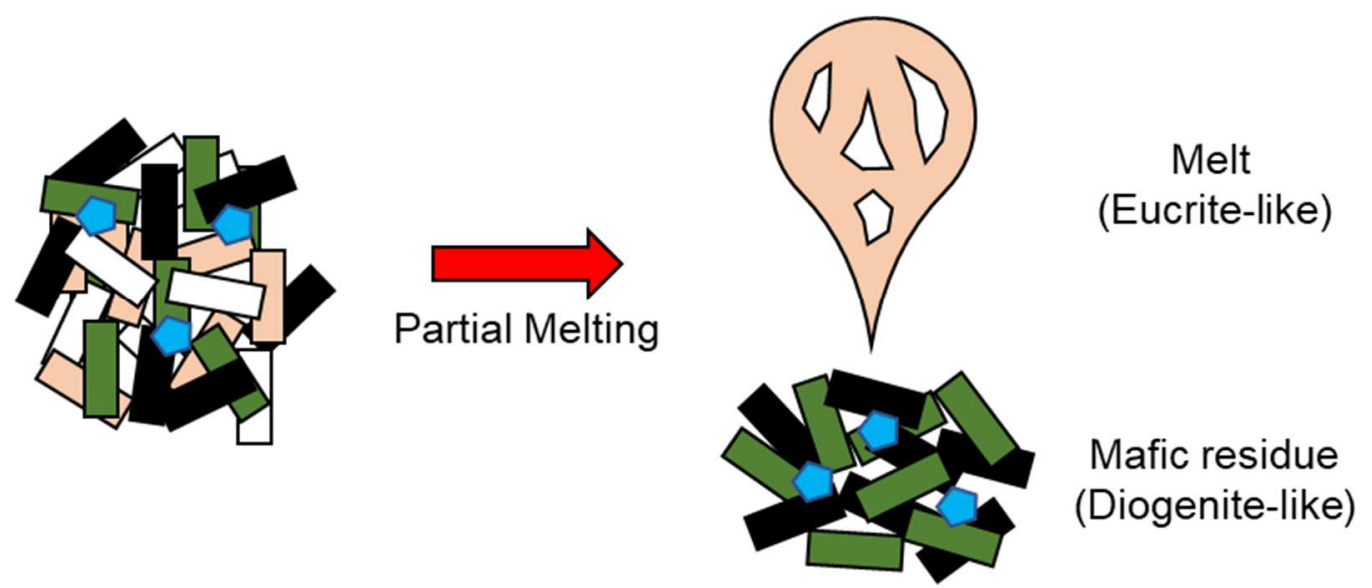

Figure 2 Schematic diagram illustrates the effect of partial melting on the Cr stable

602 isotope composition of Vesta. The white and light pink bars are felsic composition, 603 while the green and black bars represent the mafic composition. The blue pentagons are 604 chromites (Cr-spinels). After partial melting, the felsic composition would mainly go 605 to the melt while the mafic composition would stay in the residues. It should be noted 606 that, the pyroxenes and chromites which are compatible to isotopically heavy $\mathrm{Cr}^{3+}$ in 607 the residues would make the residue have higher $\mathrm{Cr}^{3+} / \mathrm{Cr}_{\text {Total }}$ and isotopically heavy for $608 \mathrm{Cr}$ isotopes. Complementarily, the melt part would be dominated in $\mathrm{Cr}^{2+}$ and 609 isotopically light for Cr. However, the diogenites are not necessarily complementary to 610 eucrites, but some other range of Vestan melts. 


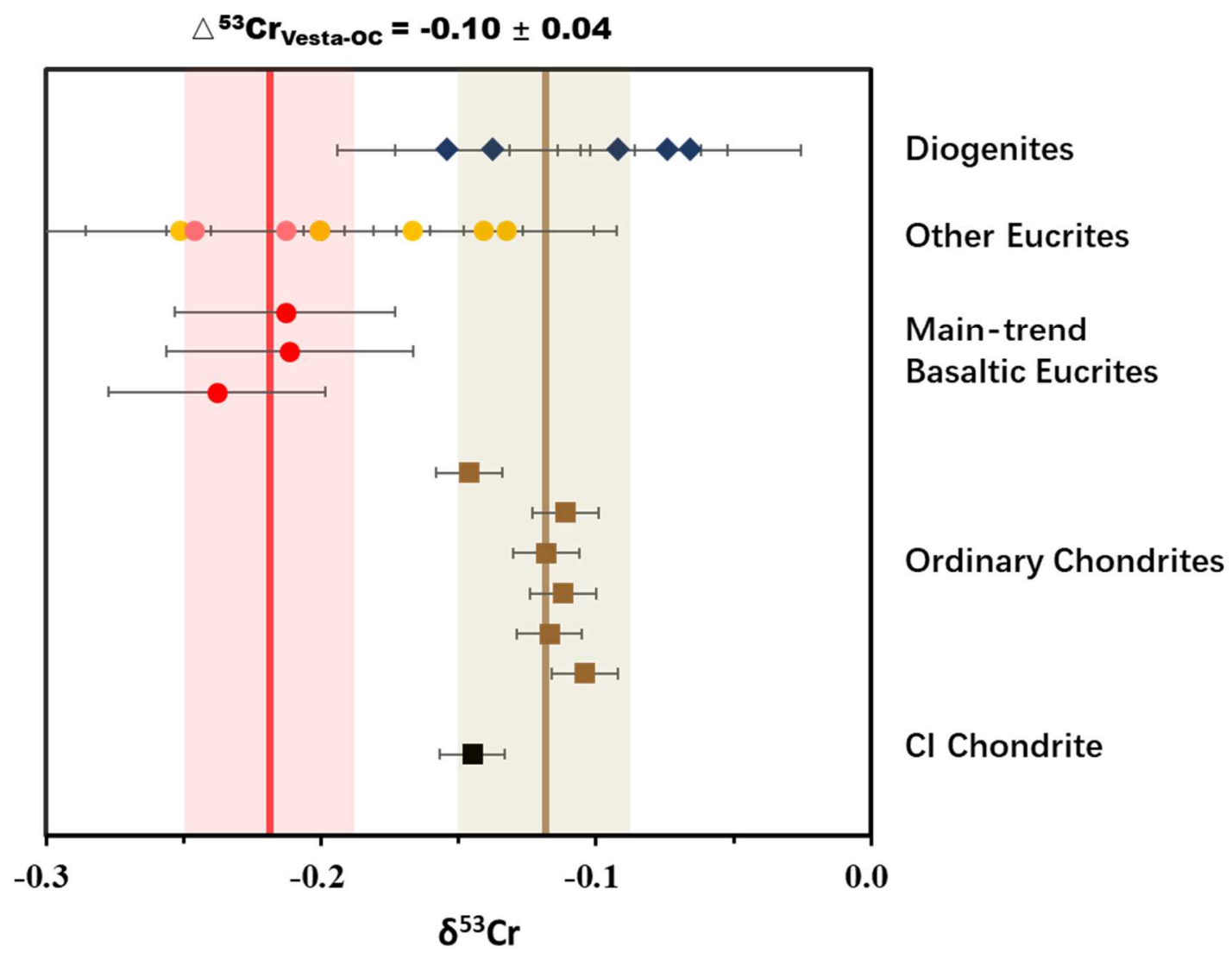

613 Figure 3 Comparison of the $\mathrm{Cr}$ isotope compositions of Diogenites (blue diamond), 614 Eucrites (yellow and red circles). The red is for main-trend basaltic eucrites, and the 615 pink is for Stannern-trend basaltic eucrites and yellow for other eucrites). Ordinary 616 chondrites are shown as brown squares and CI chondrite is shown as a black square. 617 The light red shade indicates the 2SD of $\mathrm{Cr}$ isotope values for three basaltic eucrites 618 which may represent the primitive Vesta, while the light brown shade is for that of 619 ordinary chondrites which may represent the building blocks for Vesta. The $\delta^{53} \mathrm{Cr}$ deficit 620 between primitive Vesta and ordinary chondrites is $\Delta^{53} \mathrm{Cr}_{\text {vesta-OC }}=-0.10 \pm 0.04$, which 621 should be equilibrium fractionation during the $\mathrm{Cr}$ loss or caused by partial melting effect 622 at a large-scale magma ocean stage. 


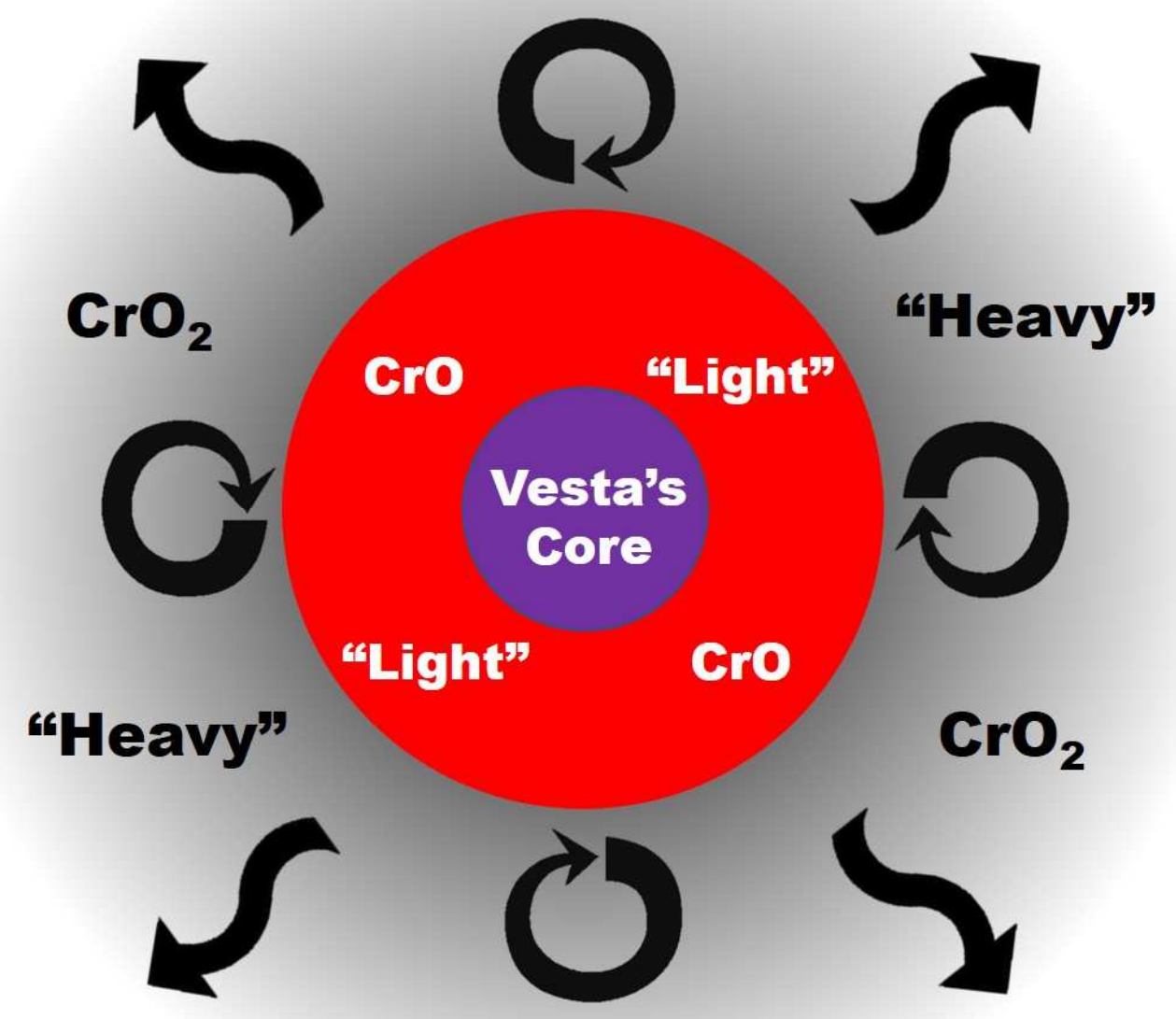

626 Figure 4 Schematic diagram illustrating the effect of volatile loss on the Cr stable 627 isotope composition of Vesta (average radius of $262.7 \mathrm{~km}$; Russell et al., 2012). In this model, within $1 \mathrm{Myr}$ after CAI (dated by the volatile-sensitive ${ }^{87} \mathrm{Rb}-{ }^{87} \mathrm{Sr}$ chronometer; Hans et al., 2013), the ${ }^{26} \mathrm{Al}-\mathrm{to}^{-}{ }^{26} \mathrm{Mg}$ decay system released sufficient heat to melt Vesta globally (Schiller et al., 2011). The temperature at the surface of the magma ocean is estimated to have been under $2300 \mathrm{~K}$. Under such conditions, the $f \mathrm{O}_{2}$ during silicatevapor equilibrium should approach the FMQ buffer. Modeling in Young et al. (2019) support near-equilibrium isotope fractionation between a magma ocean and its vapour atmosphere during planetesimal evaporation. At this $f \mathrm{O}_{2}, \mathrm{Cr}$ in the vapour $\left(\mathrm{CrO}_{2}\right)$ is more oxidized than in the melt at equilibrium (CrO). Accordingly, equilibrium fractionation produces a residual melt isotopically lighter than the vapour. The core only contains $1 \sim 3 \%$ of Vesta's Cr budget, and core formation likely did not induce Cr isotope 638 fractionation. 
Table $1 \mathrm{Cr}$ stable isotope, $\mathrm{Cr}$ content and $\mathrm{Mg} \#$ data of HED meteorites

\begin{tabular}{|c|c|c|c|c|c|c|c|}
\hline Sample & $\begin{array}{c}\text { Fal1/Fi } \\
\text { nd }\end{array}$ & Type & $\begin{array}{c}\mathrm{Cr} \\
(\mathrm{ppm})\end{array}$ & $\mathrm{Mg} \#$ & $\delta^{53} \mathrm{Cr}$ & $2 \mathrm{SD}$ & $\mathrm{N}$ \\
\hline Pasamonte & fall & Eucrite-pmict & 1750 & 38 & -0.27 & 0.06 & 2 \\
\hline replicate & & & & & -0.23 & 0.05 & 2 \\
\hline average & & & & & -0.25 & 0.06 & 4 \\
\hline Stannern & fall & Eucrite-mmict & 2041 & 38 & -0.22 & 0.04 & 2 \\
\hline replicate & & & & & -0.21 & 0.04 & 2 \\
\hline average & & & & & -0.21 & 0.04 & 4 \\
\hline Jonzac & fall & Eucrite-mmict & 2501 & 41 & -0.21 & 0.04 & 2 \\
\hline replicate & & & & & -0.22 & 0.04 & 2 \\
\hline average & & & & & -0.21 & 0.04 & 4 \\
\hline Juvinas & fall & Eucrite-mmict & 2100 & 42 & -0.26 & 0.04 & 2 \\
\hline replicate & & & & & -0.22 & 0.04 & 2 \\
\hline average & & & & & -0.24 & 0.04 & 4 \\
\hline Bouvante & find & Eucrite-mmict & 2106 & 36 & -0.25 & 0.04 & 2 \\
\hline Came1 Donga & find & Eucrite-mmict & 2232 & 40 & -0.21 & 0.04 & 2 \\
\hline Moore County & fall & Eucrite-cm & 2699 & 49 & -0.17 & 0.04 & 2 \\
\hline Pomozdino & find & Eucrite-cm & 3237 & 78 & -0.13 & 0.04 & 2 \\
\hline Serra de Magé & fall & Eucrite- $\mathrm{cm}$ & 2962 & 59 & -0.20 & 0.05 & 2 \\
\hline & & Eucrite-Mg & & & & & \\
\hline EET 87548 & find & rich & 5673 & 54 & -0.20 & 0.04 & 4 \\
\hline EET 87542 & find & Eucrite-br & 2212 & 40 & -0.14 & 0.04 & 2 \\
\hline EET 79002 & find & Diogenite & 5068 & 74 & -0.14 & 0.04 & 2 \\
\hline Tatahouine & fall & Diogenite & 6122 & 76 & -0.09 & 0.04 & 2 \\
\hline LAP 03569 & find & Diogenite & 6780 & 75 & -0.07 & 0.04 & 2 \\
\hline Shalka & fall & Diogenite & 4404 & 75 & -0.15 & 0.04 & 4 \\
\hline Johns town* & fall & Diogenite & 5700 & 75 & -0.07 & 0.01 & 1 \\
\hline BHVO-2 & & Basalt & 280 & & -0.13 & 0.04 & 1 \\
\hline DTS-1 & & Dunite & 3990 & & -0.08 & 0.04 & 2 \\
\hline PCC-1 & & Peridotite & 2730 & & -0.10 & 0.04 & 2 \\
\hline
\end{tabular}

642 Note: the $\mathrm{Cr}$ content and $\mathrm{Mg} \#$ (the ratio of $\mathrm{Mg}$ to the sum of $\mathrm{Mg}$ and $\mathrm{Fe}$ on an atomic 643 basis) data are in these literature (Barrat et al., 2000; 2008; Bonnand et al., 2016b; 644 Lugmair and Shukolyukov, 1998; Schoenberg et al., 2016; Warren et al., 2009). One 645 data marked * (Johnstone) is from Bonnand et al. (2016b). 
648

Angel, R., Gasparik, T. and Finger, L. (1989) Crystal structure of a Cr ${ }^{2+}$-bearing pyroxene. Am. Mineral. 74, 599-603.

Barrat, J.-A., Blichert-Toft, J., Gillet, P. and Keller, F. (2000) The differentiation of eucrites: the role of in situ crystallization. Meteorit. Planet. Sci. 35, 1087-1100.

Barrat, J.-A., Yamaguchi, A., Greenwood, R., Bohn, M., Cotten, J., Benoit, M. and Franchi, I. (2007) The Stannern trend eucrites: Contamination of main group eucritic magmas by crustal partial melts. Geochim. Cosmochim. Acta 71, 4108-4124.

Barrat, J.-A., Yamaguchi, A., Greenwood, R., Benoit, M., Cotten, J., Bohn, M. and Franchi, I. (2008) Geochemistry of diogenites: Still more diversity in their parental melts. Meteorit. Planet. Sci. 43, 1759-1775.

Bartels, K. and Grove, T. (1991) High-pressure experiments on magnesian eucrite compositions-Constraints on magmatic processes in the eucrite parent body. Proc. Lunar Planet. Sci. 21, 351-365.

Beck, A.W. and McSween, H.Y. (2010) Diogenites as polymict breccias composed of orthopyroxenite and harzburgite. Meteorit. Planet. Sci. 45, 850-872.

Beck, P., Barrat, J.A., Grisolle, F., Quirico, E., Schmitt, B., Moynier, F., Gillet, P. and Beck, C. (2011) NIR spectral trends of HED meteorites: Can we descriminate between the magmatic evolution, mechanical mixing and observation geometry effects? Icarus 215, 560-571

Bédard, J.H. (2007). Trace element partitioning coefficients between silicate melts and orthopyroxene: Parameterizations of D variations. Chem. Geol. 244, 263-303.

Bédard, J.H. (2010) Parameterization of the $\mathrm{Fe}=\mathrm{Mg}$ exchange coefficient $\left(\mathrm{K}_{\mathrm{d}}\right)$ between clinopyroxene and silicate melts. Chem. Geol. 274, 169-176.

Bell, A. S., Burger, P. V., Le, L., Shearer, C. K., Papike, J. J., Sutton, S. R., Newville M. and Jones, J. (2014). XANES measurements of $\mathrm{Cr}$ valence in olivine and their applications to planetary basalts. Am. Mineral. 99, 1404-1412.

Berry, A.J. and O'Neill, H.S.C. (2004) AXANES determination of the oxidation state of chromium in silicate glasses. Am. Mineral. 89, 790-798.

Berry, A.J., O'Neill, H.S.C., Scott, D.R., Foran, G.J. and Shelley, J. (2006) The effect of composition on $\mathrm{Cr}^{2+} / \mathrm{Cr}^{3+}$ in silicate melts. Am. Mineral. 91, 1901-1908.

Binzel, R.P. and Xu, S. (1993) Chips off of Asteroid 4 Vesta: Evidence for the Parent Body of Basaltic Achondrite Meteorites. Science 260, 186-191.

Bloom, H.E., Chen, H., Fegley, B., Lodders, K., and Wang, K. (2018). Potassium Isotope Compositions of Carbonaceous and Ordinary Chondrites: Implications on the Origin of Volatile Depletion in the Early Solar System. 49th Lunar Planet. Sci. Conf. Texas. \#1193 (abstr.)

Bonnand, P., Parkinson, I.J. and Anand, M. (2016a) Mass dependent fractionation of stable chromium isotopes in mare basalts: Implications for the formation and the differentiation of the Moon. Geochim. Cosmochim. Acta 175, 208-221.

Bonnand, P., Williams, H.M., Parkinson, I.J., Wood, B.J. and Halliday, A.N. (2016b) Stable chromium isotopic composition of meteorites and metal-silicate experiments: Implications for fractionation during core formation. Earth Planet. Sci. Lett. 435, 14-21.

Bowman, L., Spilde, M. and Papike, J. (1997) Automated energy dispersive spectrometer modal 
analysis applied to the diogenites. Meteorit. Planet. Sci. 32, 869-875.

690 Boyce, J.W., Treiman, A.H., Guan, Y., Ma, C., Eiler, J.M., Gross, J., Greenwood, J.P. and Stolper, 691 E.M. (2015) The chlorine isotope fingerprint of the lunar magma ocean. Sci. adv. 1, e1500380. Boyce, J. W., Kanee, S. A., McCubbin, F. M., Barnes, J. J., Bricker, H., and Treiman, A. H.

693 (2018). Early loss, fractionation, and redistribution of chlorine in the Moon as revealed by the 694 low-Ti lunar mare basalt suite. Earth Planet. Sci. Lett. 500, 205-214.

695 Burns, R.G. (1975) On the occurrence and stability of divalent chromium in olivines included in 696 diamonds. Contrib. Mineral. Petrol. 51, 213-221.

697 Chase, M. (1998) NIST_JANAF Thermochemical Tables (Journal of Physical and Chemical 698 Reference Data Monograph No. 9). American Institute of Physics.

699 Chen, G., Bai, Y., Zeng, R. J., and Qin, L. (2019). Effects of different metabolic pathways and 700 environmental parameters on $\mathrm{Cr}$ isotope fractionation during $\mathrm{Cr}(\mathrm{VI})$ reduction by extremely 701 thermophilic bacteria. Geochimica et Cosmochimica Acta. 256, 135-146.

702 Day, J.M.D., Walker, R.J., Qin, L. and Rumble III, D. (2012) Late accretion as a natural 703 consequence of planetary growth. Nature Geoscience 5, 614-617.

704 Day, J.M.D. and Moynier, F. (2014) Evaporative fractionation of volatile stable isotopes and their 705 bearing on the origin of the Moon. Phil. Trans. R. Soc. A. 372, 20130259.

706 Delaney, J.S., Prinz, M. and Takeda, H. (1984) The polymict eucrites. Journal of Geophysical 707 Research: Solid Earth 89, C251-C288.

708 Dhaliwal, J.K., Day, J.M.D. and Moynier F. (2018) Volatile element loss during planetary magma 709 ocean phases. Icarus 300, 249-260.

710 Dreibus, G. and Wänke, H. (1980) The bulk composition of the eucrite parent asteroid and its 711 bearing on planetary evolution. Zeitschrift für Naturforschung A 35, 204-216.

712 Eugster, O., and Michel, T. (1995). Common asteroid break-up events of eucrites, diogenites, 713 and howardites and cosmic-ray production rates for noble gases in achondrites. Geochimica et 714 Cosmochimica Acta. 59, 177-199.

715 Farkaš, J., Chrastný, V., Novák, M., Čadkova, E., Pašava, J., Chakrabarti, R., Jacobsen, S.B., 716 Ackerman, L. and Bullen, T.D. (2013) Chromium isotope variations $\left(\delta^{53 / 52} \mathrm{Cr}\right)$ in mantle-derived 717 sources and their weathering products: Implications for environmental studies and the evolution 718 of $\delta^{53 / 52} \mathrm{Cr}$ in the Earth's mantle over geologic time. Geochim. Cosmochim. Acta 123, 74-92.

719 Greenwood, R.C., Franchi, I.A., Jambon, A. and Buchanan, P.C. (2005) Widespread magma 720 oceans on asteroidal bodies in the early solar system. Nature 435, 916-918.

721 Greenwood, R.C., Franchi, I.A., Scott, E.R.D., Barrat, J.A. and Norman, M. (2009) Oxygen 722 Isotope Variation in the HEDs: How Homogeneous is Vesta? 72nd Annual Meteoritical Society 723 Meeting, Nancy. \#5436 (abstr.).

724 Greenwood, R.C., Barrat, J.-A., Yamaguchi, A., Franchi, I.A., Scott, E.R., Bottke, W.F. and 725 Gibson, J.M. (2014) The oxygen isotope composition of diogenites: Evidence for early global 726 melting on a single, compositionally diverse, HED parent body. Earth Planet. Sci. Lett. 390, $727 \quad 165-174$.

728 Grossman, L., Beckett, J. R., Fedkin, A. V., Simon, S. B., \& Ciesla, F. J. (2008). Redox 729 conditions in the solar nebula: Observational, experimental, and theoretical constraints. 730 Reviews in Mineralogy and Geochemistry 68, 93-140.

731 Hans, U., Kleine, T. and Bourdon, B. (2013) Rb-Sr chronology of volatile depletion in 732 differentiated protoplanets: BABI, ADOR and ALL revisited. Earth Planet. Sci. Lett. 374, 204- 
734 Hin, R., Coath, C.D., Carter, P.J., Nimmo, F., Laim Y.J., Pogge Von Strandman, P., Willbold, M., 735 Leinhardt, Z., Walter, M. and Elliot, T. Magnesium isotopic evidence that vapour loss shapes 736 planetary composition. Nature 549, 511-515.

737 Hublet, G., Debaille, V., Wimpenny, J. and Yin, Q.Z. (2017) Differentiation and magmatic activity 738 in Vesta evidenced by ${ }^{26} \mathrm{Al}-{ }^{26} \mathrm{Mg}$ dating in eucrites and diogenites. Geochim. Cosmochim. Acta 739 218, 73-97.

740 Jones, J.H. (1984) The composition of the mantle of the eucrite parent body and the origin of 741 eucrites. Geochim. Cosmochim. Acta 48, 641-648.

742 Kallemeyn, G.W., Rubin, A.E., Wang, D. and Wasson, J.T. (1989) Ordinary chondrites: Bulk 743 compositions, classification, lithophile-element fractionations and composition-petrographic 744 type relationships. Geochim. Cosmochim. Acta 53, 2747-2767.

745 Karner, J., Papike, J., Shearer, C., McKay, G., Le, L. and Burger, P. (2007) Valence state 746 partitioning of $\mathrm{Cr}$ and $\mathrm{V}$ between pyroxene-melt: Estimates of oxygen fugacity for martian basalt 747 QUE 94201. Am. Mineral. 92, 1238-1241.

748 Kato, C., Moynier, F., Valdes, M.C., Dhaliwal, J.K. and Day, J.M.D. (2015) Extensive volatile 749 loss during formation and differentiation of the Moon. Nat. Commun. 6, 7617.

750 Kato, C. and Moynier, F. (2017) Gallium isotopic evidence for extensive volatile loss from the 751 Moon during its formation. Sci. Adv. 3, e1700571.

752 Keil, K. (2002) Geological history of asteroid 4 Vesta: The "smallest terrestrial planet". Asteroids 753 III (eds. W. F. Bottke et al.) Univ. of Arizona Press, Tucson, pp. 573-584.

754 Lamoreaux R H, Hildenbrand D L. (1984) High temperature vaporization behavior of oxides. I. 755 Alkali metal binary oxides. Journal of physical and chemical reference data. 13, 151-173.

756 Lamoreaux R.H., Hildenbrand D.L. and Brewer L. (1987) High-Temperature Vaporization 757 Behavior of Oxides II. Oxides of Be, Mg, Ca, Sr, Ba, B, Al, Ga, In, TI, Si, Ge, Sn, Pb, Zn, Cd, 758 and $\mathrm{Hg}$. Journal of physical and chemical reference data. 16, 419-443.

759 Li, J., O'Neil, H.S.C. and Seifert, F. (1995) Subsolidus Phase Relations in the System MgO$760 \mathrm{SiO}_{2}-\mathrm{Gr}-\mathrm{O}$ in Equilibrium with Metallic $\mathrm{Cr}$, and their Significance for the Petrochemistry of 761 Chromium. J. Petrol. 36, 107-132.

762 Lugmair, G. and Shukolyukov, A. (1998) Early solar system timescales according to ${ }^{53} \mathrm{Mn}-{ }^{53} \mathrm{Cr}$ 763 systematics. Geochim. Cosmochim. Acta 62, 2863-2886.

764 Lunning, N. G., McSween, H. Y., Tenner, T. J., Kita, N. T. and Bodnar, R. J. (2015). Olivine and 765 pyroxene from the mantle of asteroid 4 Vesta. Earth Planet. Sci. Lett. 418, 126-135.

766 Magna, T., Šimčíková, M. and Moynier, F. (2014) Lithium systematics in howardite-eucrite767 diogenite meteorites: Implications for crust-mantle evolution of planetary embryos. Geochim.

768 Cosmochim. Acta 125, 131-145.

769 Mallmann, G. and O'Neill, H.S.C. (2009) The crystal/melt partitioning of $V$ during mantle melting 770 as a function of oxygen fugacity compared with some other elements (Al, P, Ca, Sc, Ti, Cr, Fe, 771 Ga, Y, Zr and Nb). J. Petrol. 50, 1765-1794.

772 Mandler, B.E. and Elkins - Tanton, L.T. (2013) The origin of eucrites, diogenites, and olivine 773 diogenites: Magma ocean crystallization and shallow magma chamber processes on Vesta. 774 Meteorit. Planet. Sci. 48, 2333-2349.

775 Mann, U., Frost, D. J., \& Rubie, D. C. (2009) Evidence for high-pressure core-mantle 
differentiation from the metal-silicate partitioning of lithophile and weakly-siderophile elements. Geochim. Cosmochim. Acta 73, 7360-7386.

Mason, B. (1967) Meteorites. American Scientist. 55, 429-455.

Mayne, R.G., McSween Jr, H.Y., McCoy, T.J., and Gale, A. (2009) Petrology of the unbrecciated eucrites. Geochim. Cosmochim. Acta 73, 794-819.

McCord, T.B., Adams, J.B. and Johnson, T.V. (1970) Asteroid Vesta: Spectral reflectivity and compositional implications. Science 168, 1445-1447.

Mittlefehldt, D.W. (2014) 1.6 - Achondrites A2 - Holland, Heinrich D, in: Turekian, K.K. (Ed.), Treatise on Geochemistry (Second Edition). Elsevier, Oxford, pp. 235-266.

Mittlefehldt, D.W. (2015) Asteroid (4) Vesta: I. The howardite-eucrite-diogenite (HED) clan of meteorites. Chem. Erde 75, 155-183.

Mittlefehldt, D.W., Peng, Z.X. and Ross, D.K. (2015) Petrology of Anomalous Eucrites, 46th Lunar Planet. Sci. Conf. Texas. \#1933 (abstr.).

Mittlefehldt, D.W., Peng, Z.X. and Mertzman, S.A. (2016) Compositions of Normal and Anomalous Eucrite-Type Mafic Achondrites, 79th Annual Meeting of the Meteoritical Society. Berlin. \#6324 (abstr.).

Mougel, B., Moynier, F., Göpel, C. and Koeberl, C. (2017) Chromium isotope evidence in ejecta deposits for the nature of Paleoproterozoic impactors. Earth Planet. Sci. Lett. 460, 105-111.

Mougel, B., Moynier, F. and Göpel, C. (2018) Chromium isotopic homogeneity between the Moon, the Earth, and enstatite chondrites. Earth Planet. Sci. Lett. 481, 1-8.

Moynier, F., Yin, Q.-Z. and Schauble, E. (2011) Isotopic evidence of Cr partitioning into Earth's core. Science 331, 1417-1420.

Moynier, F., Day, J.M.D., Okui, W., Yokoyama, T., Bouvier, A., Walker, R.J. and Podosek, F.A. (2012) Planetary-scale strontium isotopic heterogeneity and the age of volatile depletion of early Solar System materials. Astrophys. J. 758, 45.

Nakajima, M. and Stevenson, D.J. (2014) Investigation of the initial state of the Moon-forming disk: Bridging SPH simulations and hydrostatic models. Icarus 233, 259-267.

O'Neill, H.S.C. and Berry, A.J. (2006) Activity coefficients at low dilution of $\mathrm{CrO}, \mathrm{NiO}$ and $\mathrm{CoO}$ in melts in the system $\mathrm{CaO}-\mathrm{MgO}-\mathrm{Al}_{2} \mathrm{O} 3-\mathrm{SiO}_{2}$ at $1400^{\circ} \mathrm{C}$ : Using the thermodynamic behaviour of transition metal oxides in silicate melts to probe their structure. Chem. Geol. 231, 77-89.

O'Neill, H.S.C. and Palme, H. (2008) Collisional erosion and the non-chondritic composition of the terrestrial planets. Philos. Trans. Roy. Soc. Lond. A 366, 4205-4238.

Paniello, R.C., Day, J.M.D. and Moynier, F. (2012a) Zinc isotopic evidence for the origin of the Moon. Nature 490, 376.

Paniello, R.C., Moynier, F., Beck, P., Barrat, J.-A., Podosek, F.A. and Pichat, S. (2012b) Zinc isotopes in HEDs: Clues to the formation of 4-Vesta, and the unique composition of Pecora Escarpment 82502. Geochim. Cosmochim. Acta 86, 76-87.

Pedersen, S. G., Schiller, M., Connelly, J. N., and Bizzarro, M. (2019). Testing accretion mechanisms of the $\mathrm{H}$ chondrite parent body utilizing nucleosynthetic anomalies. Meteorit. Planet. Sci. in press. https://doi.org/10.1111/maps.13269

Pringle, E.A., Savage, P.S., Badro, J., Barrat, J.A., and Moynier, F. (2013) Redox state during core formation on asteroid 4-Vesta. Earth Planet. Sci. Lett. 373, 75-82.

Pringle, E.A. and Moynier, F. (2017) Rubidium isotopic composition of the Earth, meteorites, and the Moon: Evidence for the origin of volatile loss during planetary accretion. Earth Planet. 
Sci. Lett. 473, 62-70.

Qin, L., Xia, J., Carlson, R. and Zhang, Q. (2015) Chromium stable isotope composition of meteorites, 46th Lunar Planet. Sci. Conf. Texas. \#2015 (abstr.).

Rammensee, W., Palme, H., \& Wanke, H. (1983). Experimental investigation of metal-silicate partitioning of some lithophile elements (Ta, Mn, V, Cr). Lunar Planet. Sci. Conf. 14, 628-629. (abstr.).

Righter, K. and Drake, M.J. (1997) A magma ocean on Vesta: Core formation and petrogenesis of eucrites and diogenites. Meteorit. Planet. Sci. 32, 929-944.

Righter, K., Sutton, S.R., Danielson, L., Pando, K. and Newville, M. (2016) Redox variations in the inner solar system with new constraints from vanadium XANES in spinels. Am. Mineral. 101, 1928-1942.

Roeder, P. and Reynolds, I. (1991) Crystallization of chromite and chromium solubility in basaltic melts. J. Petrol. 32, 909-934.

Russell, C., Raymond, C., Coradini, A., McSween, H., Zuber, M.T., Nathues, A., De Sanctis, M.C., Jaumann, R., Konopliv, A. and Preusker, F. (2012) Dawn at Vesta: Testing the protoplanetary paradigm. Science 336, 684-686.

Ruzicka, A., Snyder, G.A. and Taylor, L.A. (1997) Vesta as the howardite, eucrite and diogenite parent body: Implications for the size of a core and for large-scale differentiation. Meteorit. Planet. Sci. 32, 825-840.

Sanborn, M.E. and Yin, Q.-Z. (2014) Chromium Isotopic Composition of the Anomalous Eucrites: An Additional Geochemical Parameter for Evaluating Their Origin, 45th Lunar Planet. Sci. Conf. Texas. \#2018. (abstr.).

Sarafian, A.R., John, T., Roszjar, J. and Whitehouse, M.J. (2017) Chlorine and hydrogen degassing in Vesta's magma ocean. Earth Planet. Sci. Lett. 459, 311-319.

Schiller, M., Baker, J., Creech, J., Paton, C., Millet, M.-A., Irving, A. and Bizzarro, M. (2011) Rapid timescales for magma ocean crystallization on the howardite-eucrite-diogenite parent body. Astrophys. J. Lett. 740, L22.

Schiller M, Connelly J N, Bizzarro M. (2017) Lead and Mg isotopic age constraints on the evolution of the HED parent body. Meteorit. Planet. Sci. 52: 1233-1243.

Schoenberg, R., Zink, S., Staubwasser, M. and Von Blanckenburg, F. (2008) The stable Cr isotope inventory of solid Earth reservoirs determined by double spike MC-ICP-MS. Chem. Geol. 249, 294-306.

Schoenberg, R., Merdian, A., Holmden, C., Kleinhanns, I.C., Haßler, K., Wille, M. and Reitter, E. (2016) The stable $\mathrm{Cr}$ isotopic compositions of chondrites and silicate planetary reservoirs. Geochim. Cosmochim. Acta 183, 14-30.

Scott, E.R., Greenwood, R.C., Franchi, I.A. and Sanders, I.S. (2009) Oxygen isotopic constraints on the origin and parent bodies of eucrites, diogenites, and howardites. Geochim. Cosmochim. Acta 73, 5835-5853.

Sharp, Z., Shearer, C., McKeegan, K., Barnes, J. and Wang, Y. (2010) The chlorine isotope composition of the Moon and implications for an anhydrous mantle. Science 329, 1050-1053. Shen, J., Liu, J., Qin, L., Wang, S.J., Li, S., Xia, J., Ke, S. and Yang, J. (2015) Chromium isotope signature during continental crust subduction recorded in metamorphic rocks. Geochem. Geophys. Geosyst. 16, 3840-3854. 
Shen, J., Qin, L., Fang, Z., Zhang, Y., Liu, J., Liu, W., Wang, F., Xiao, Y., Yu, H. and Wei, S. (2018) High-temperature inter-mineral $\mathrm{Cr}$ isotope fractionation: A comparison of ionic model predictions and experimental investigations of mantle xenoliths from the North China Craton. Earth Planet. Sci. Lett. 499, 278-290.

Siebert, J., Badro, J., Antonangeli, D. and Ryerson, F.J. (2013) Terrestrial Accretion Under Oxidizing Conditions. Science 339, 1194-1197.

Siebert, J., Sossi, P.A., Blanchard, I., Mahan, B., Badro, J. and Moynier, F. (2018) Chondritic $\mathrm{Mn} / \mathrm{Na}$ ratio and limited post-nebular volatile loss of the Earth. Earth Planet. Sci. Lett. 485, $130-$ 139.

Sossi, P.A., Moynier, F. and van Zuilen, K. (2018) Volatile loss following cooling and accretion of the Moon revealed by chromium isotopes. Proc. Natl. Acad. Sci. doi/10.1073/pnas.1809060115

Sossi, P. A., and Fegley Jr, B. (2018). Thermodynamics of element volatility and its application to planetary processes. Reviews in Mineralogy and Geochemistry, 84, 393-459.

Sossi P.A., Klemme S., O'Neill H. St.C., Berndt J. and Moynier F. (2019). Evaporation of moderately volatile elements from silicate melts: experiments and theory. Geochim. Cosmochim. Acta. In press. doi: 10.1016/j.gca.2019.06.021

Stolper, E. (1977) Experimental petrology of eucritic meteorites. Geochim. Cosmochim. Acta 41, 587-611.

Tian, Z., Chen, H., Fegley, B.J., Lodders, K., Barrat, J.A. and Wang, K. (2018) Potassium Isotope Differences Among Chondrites, Earth, Moon, Mars, and 4-Vesta - Implication on the Planet Accretion Mechanisms, 49th Lunar Planet. Sci. Conf. Texas. \#2083 (abstr.)

Toplis, M. J. (2005). The thermodynamics of iron and magnesium partitioning between olivine and liquid: criteria for assessing and predicting equilibrium in natural and experimental systems. Contributions to Mineralogy and Petrology. 149, 22-39.

Trinquier, A., Birck, J.-L. and Allègre, C.J. (2007) Widespread ${ }^{54} \mathrm{Cr}$ heterogeneity in the inner solar system. Astrophys. J. 655, 1179.

Trinquier, A., Birck, J.L., Allègre, C.J., Göpel, C. and Ulfbeck, D. (2008) ${ }^{53} \mathrm{Mn}-{ }^{53} \mathrm{Cr}$ systematics of the early Solar System revisited. Geochim. Cosmochim. Acta 72, 5146-5163.

Trinquier, A., Elliott, T., Ulfbeck, D., Coath, C., Krot, A. N., and Bizzarro, M. (2009). Origin of nucleosynthetic isotope heterogeneity in the solar protoplanetary disk. Science 324, 374-376.

Visscher, C. and Fegley Jr, B. (2013) Chemistry of impact-generated silicate melt-vapor debris disks. Astrophys. J. Lett. 767, L12.

Wadhwa, M. (2008) Redox conditions on small bodies, the Moon and Mars. Reviews in Mineralogy and Geochemistry 68, 493-510.

Wade, J., \& Wood, B. J. (2001). The Earth's 'missing'niobium may be in the core. Nature 409, 75-78.

Wang, K. and Jacobsen, S.B. (2016) Potassium isotopic evidence for a high-energy giant impact origin of the Moon. Nature 538, 487-490.

Wänke, H. and Dreibus, G. (1980) The bulk composition of the eucrite parent asteroid and its bearing on planetary evolution. Zeitschrift für Naturforschung A 35, 204-216.

Warren, P.H., Kallemeyn, G.W., Huber, H., Ulff-Møller, F. and Choe, W. (2009) Siderophile and other geochemical constraints on mixing relationships among HED-meteoritic breccias. Geochim. Cosmochim. Acta 73, 5918-5943. 
907 Wasson, J.T. and Kallemeyn, G.W. (1988) Compositions of chondrites. Phil. Trans. R. Soc. A. 908 325, 535-544.

909 Wilson, L. and Keil, K. (2017) Arguments for the non-existence of magma oceans in asteroids.

910 In Planetesimals: Early Differentiation and Consequences for Planets. Cambridge University

911 Press, Cambridge Planetary Science, 159-179.

912 Wood, B.J., Wade, J. and Kilburn, M.R. (2008) Core formation and the oxidation state of the

913 Earth: Additional constraints from Nb, V and Cr partitioning. Geochim. Cosmochim. Acta 72 ,

914 1415-1426.

915 Xia, J., Qin, L., Shen, J., Carlson, R.W., Ionov, D.A. and Mock, T.D. (2017) Chromium isotope

916 heterogeneity in the mantle. Earth Planet. Sci. Lett. 464, 103-115.

917 Young, E. D., Shahar, A., Nimmo, F., Schlichting, H. E., Schauble, E. A., Tang, H. and Labidi, J.

918 (2019). Near-equilibrium isotope fractionation during planetesimal evaporation. Icarus. 323, 1-

91915

920 Zhu, K., Liu, J., Moynier, F., Qin, L., Alexander, C. M. D., and He, Y. (2019a). Chromium Isotopic

921 Evidence for an Early Formation of Chondrules from the Ornans CO Chondrite. Astrophys.

922 J., 873, 82.

923 Zhu, K., Moynier, F., Barrat, J.-A., Wielandt, D., Larsen, K. and Bizzarro, M. (2019b). Timing

924 and origin of the angrite parent body inferred from $\mathrm{Cr}$ isotopes. Astrophys. J. Lett., 877, L13 